\title{
Apparent optical properties of the Canadian Beaufort Sea - Part 1: Observational overview and water column relationships
}

\author{
D. Antoine ${ }^{1, *}$, S. B. Hooker ${ }^{2}$, S. Bélanger ${ }^{3}$, A. Matsuoka ${ }^{4}$, and M. Babin ${ }^{1,4}$ \\ ${ }^{1}$ Laboratoire d'Océanographie de Villefranche (LOV), UMR7093, Centre National de la Recherche Scientifique (CNRS) and \\ Université Pierre et Marie Curie, Paris 06, Villefranche-sur-Mer, France \\ ${ }^{2}$ NASA Goddard Space Flight Center, Ocean Ecology Laboratory, Greenbelt, Maryland 20771, USA \\ ${ }^{3}$ Université du Québec à Rimouski, Département de biologie, chimie et géographie and BORÉAS, Rimouski (Québec), \\ Canada \\ ${ }^{4}$ Unité Mixte Internationale Takuvik, Centre National de la Recherche Scientifique (CNRS) and Université Laval, Avenue de \\ la Médecine, Québec City (Québec), Canada \\ *now at: Curtin University, Department of Imaging and Applied Physics, Remote Sensing and Satellite Research Group, \\ Perth, WA 6845, Australia
}

Correspondence to: D. Antoine (antoine@obs-vlfr.fr)

Received: 2 February 2013 - Published in Biogeosciences Discuss.: 1 March 2013

Revised: 30 May 2013 - Accepted: 5 June 2013 - Published: 4 July 2013

\begin{abstract}
A data set of radiometric measurements collected in the Beaufort Sea (Canadian Arctic) in August 2009 (Malina project) is analyzed in order to describe apparent optical properties (AOPs) in this sea, which has been subject to dramatic environmental changes for several decades. The two properties derived from the measurements are the spectral diffuse attenuation coefficient for downward irradiance, $K_{\mathrm{d}}$, and the spectral remote sensing reflectance, $R_{\mathrm{rs}}$. The former controls light propagation in the upper water column. The latter determines how light is backscattered out of the water and becomes eventually observable from a satellite ocean color sensor. The data set includes offshore clear waters of the Beaufort Basin as well as highly turbid waters of the Mackenzie River plumes. In the clear waters, we show $K_{\mathrm{d}}$ values that are much larger in the ultraviolet and blue parts of the spectrum than what could be anticipated considering the chlorophyll concentration. A larger contribution of absorption by colored dissolved organic matter (CDOM) is responsible for these high $K_{\mathrm{d}}$ values, as compared to other oligotrophic areas. In turbid waters, attenuation reaches extremely high values, driven by high loads of particulate materials and also by a large CDOM content. In these two extreme types of waters, current satellite chlorophyll algorithms fail. This questions the role of ocean color remote sensing in the Arctic when $R_{\mathrm{rs}}$ from only the blue and green bands are used.
\end{abstract}

Therefore, other parts of the spectrum (e.g., the red) should be explored if one aims at quantifying interannual changes in chlorophyll in the Arctic from space. The very peculiar AOPs in the Beaufort Sea also advocate for developing specific light propagation models when attempting to predict light availability for photosynthesis at depth.

\section{Introduction}

Current dramatic evolutions of the Arctic environment include an increase in atmosphere temperature larger than elsewhere (Zhang, 2005), a summer ice melting that accelerates as compared to current model predictions (Stroeve et al., 2005), carbon-rich permafrost thawing on most coastal fringes (Schuur et al., 2008), and cloudiness changes (Eastman and Warren, 2010). These major changes in physical and chemical forcing inevitably lead to significant modifications of the underwater light environment of Arctic waters, through their impact on seawater optical properties. A cascade of effects is to be expected on all light-mediated or light-controlled processes, including photosynthesis and photochemical reactions, and the heating rate of the upper layers. 
Quantifying the impact of current changes in optical properties requires knowledge of them prior to these changes. Establishing such a baseline is actually difficult because optical properties of Arctic waters have been scarcely sampled until now. Reports have been made of inherent optical properties (IOPs, sensu Preisendorfer, 1961), for instance in surface waters of the Chukchi Plateau (Pegau, 2002) or in the Beaufort and Chukchi seas in August 2000 (Wang et al., 2005). The Malina Leg2b cruise has brought additional IOP observations, in particular of particulate absorption (Bélanger et al., 2013), absorption by colored dissolved organic matter (CDOM; Matsuoka et al., 2013), and particulate backscattering (Doxaran et al., 2012). Other data were essentially collected in relation to quantifying upper ocean heating rates close to or below sea ice (Pegau, 2002, and references therein). Observations of apparent optical properties (AOPs) in the Arctic are even more rare. Smith (1973) reported irradiance measurements made below a $5 \mathrm{~m}$ thick icecap in the central Arctic (on Fletcher's ice island T-3), and Maykut and Grenfell (1975) reported irradiance measurements also made under sea ice ( $\sim 1-2 \mathrm{~m}$ thick) near Point Barrow, Alaska. Smith (1973) concluded that Arctic waters were among the clearest in the world known at that time. The rationale in the 1970s and 1980s was definitely to understand under-ice conditions, which were prevailing and considered as the typical Arctic environment, whereas a different perspective now emerges because large areas are free of ice in summer.

In the 1980s, Topliss et al. (1989) performed spectral $K_{\mathrm{d}}$ measurements in the northern Baffin Bay, eastern Canadian Arctic, suggesting that the waters from this region departed significantly from the so-called case-1 waters (Morel and Prieur, 1977) because of the presence of an anomalously high particulate scattering background, as well as a greater contribution of the degradation products to blue light attenuation. Accordingly, Mitchell (1992) noticed an important contribution of yellow substances to the blue light attenuation in Fram Strait and in the Barents Sea relative to the polar Antarctic waters. He showed that polar phytoplankton tend to present higher pigment-packaging effect relative to temperate latitudes that reduces their efficiency to absorb light for a given concentration of chlorophyll $a(\mathrm{Chl} a)$.

Historical observations were complemented only much more recently by measurements made in ice-free waters (Wang and Cota, 2003; Matsuoka et al., 2007, 2009, 2011; Hill, 2008; Ben Mustapha et al., 2012; Brunelle et al., 2012), and no other measurements have been reported in between in the open literature, at least to our knowledge. Therefore, attenuation and reflectance properties of Arctic waters are still poorly known.

Here we report on an intense program of radiometric data collection that was carried out during the Malina Leg2b cruise in the Canadian Beaufort Sea in August of 2009. The large number of sampled stations makes this effort appropriate to characterize the underwater light field in this region.
The objective is to describe the data set in terms of the spectral diffuse attenuation coefficient for downward irradiance, $K_{\mathrm{d}}(\lambda)$, and the spectral remote sensing reflectance, $R_{\mathrm{rs}}(\lambda)$. The former controls light propagation in the upper water column and therefore modulates the heating rate and the light availability for photosynthesis or photochemical reactions. The latter is a measure of the light backscattered out of the water and eventually observable from a satellite ocean color sensor.

The different light environments that were encountered are first described, and a classification is proposed for the stations that were sampled in a variety of environments. Spectral characteristics and membership to either case- 1 or case- 2 waters is discussed, and the results from a search for bio-optical relationships are presented. The implications of our findings on the modeling of primary production and the remote sensing of $\mathrm{Chl} a$ in the Arctic are finally discussed.

A second objective of this paper and especially of its companion part II paper (Hooker et al., 2013) is to illustrate the capabilities of a next-generation profiler system that we used for collection of the radiometric data. This instrument provides high-quality radiometric measurements over an extended spectral range as compared to previously used profiling systems, which is particularly adapted to the multifaceted Arctic environment.

\section{Methods}

\subsection{Deriving AOPs from in-water profiles of radiometric quantities}

Vertical profiles of radiometric quantities were collected during Malina Leg2b using a biospherical Compact-Optical Profiling System (C-OPS). The rationale for the development of this next-generation in-water profiling system is provided in the companion paper (Hooker et al., 2013), along with detailed description of its design and operation, and further demonstration of its capability in deriving high-accuracy radiometric data in particular just below the surface. Suffice it to say here that this instrument allows getting high-resolution vertical profiles of the downward plane irradiance, $E_{\mathrm{d}}$, and the upwelling radiance at nadir, $L_{\mathrm{u}}$, in the following $19 \mathrm{spec}-$ tral bands: $320,340,380,395,412,443,465,490,510,532$, $555,560,625,665,670,683,710,780 \mathrm{~nm}$ and photosynthetically active radiation (PAR). The high dynamic range of the microradiometers used in the C-OPS in principle allows getting $E_{\mathrm{d}}$ and $L_{\mathrm{u}}$ over 8 orders of magnitude, from high irradiances typical of the surface layer during a sunny day in clear waters to dim irradiances under cloudy skies or at large depth or in extremely turbid waters. The C-OPS was deployed from a $12 \mathrm{~m}$ barge in parallel to, but at distance from, the Amundsen icebreaker main operations. This protocol allowed avoiding any ship perturbation, either due to shadowing from the hull and superstructures or due to mixing of the upper layers. 
It also allowed an easy and unobstructed deployment of the deck reference using a telescoping mast (Hooker, 2010) for collection of above-surface downward irradiance $\left(E_{\mathrm{d}}\left(0^{+}\right)\right.$or $E_{\mathrm{s}}$; see below), and getting close to icecaps for specific casts.

The processing of these data is based here on a wellestablished methodology (Smith and Baker, 1984) that was evaluated in an international round robin (Hooker et al., 2001) and shown to be capable of agreement at the $1 \%$ level when the processing options were as similar as possible. Complete details of the terms and dependencies are available in the Ocean Optics Protocols (hereafter, the Protocols), which initially adhered to the Joint Global Ocean Flux Study (JGOFS) sampling procedures (JGOFS, 1991) and defined the standards for NASA calibration and validation activities (Mueller and Austin, 1992). Over time, the Protocols were initially revised (Mueller and Austin, 1995) and then updated annually (Mueller 2000, 2002, 2003).

The Protocols are detailed, so only a brief overview for obtaining data products from vertical profiles of upwelling radiance $\left(L_{\mathrm{u}}\right)$ plus upward and downward irradiance $\left(E_{\mathrm{u}}\right.$ and $E_{\mathrm{d}}$, respectively) is presented here. In-water radiometric quantities in physical units, $\aleph$ (i.e., $L_{\mathrm{u}}, E_{\mathrm{u}}$, or $E_{\mathrm{d}}$ ), are normalized with respect to simultaneous measurements of the global solar irradiance, $E_{\mathrm{d}}\left(0^{+}, \lambda, t\right)$, with $t$ explicitly expressing the time dependence, according to

$\aleph\left(z, \lambda, t_{0}\right)=\aleph(z, \lambda, t) \frac{E_{\mathrm{d}}\left(0^{+}, \lambda, t_{0}\right)}{E_{\mathrm{d}}\left(0^{+}, \lambda, t\right)}$,

where $\aleph\left(z, \lambda, t_{0}\right)$ identifies the radiometric parameters as they would have been recorded at all depths $z$ at the same time $t_{0}$, and $t_{0}$ is generally chosen to coincide with the start of data acquisition. For simplicity, the variable $t$ is omitted in the following text. In addition, any data collected when the vertical tilt of the profiler exceeds $5^{\circ}$ are excluded from the ensuing analysis.

After normalization and tilt filtering, a near-surface portion of $E_{\mathrm{d}}(z, \lambda)$ centered at $z_{0}$ and having homogeneous optical properties (verified with temperature and attenuation parameters) extending from $z_{1}=z_{0}+\Delta z$ and $z_{2}=z_{0}-\Delta z$ is established separately for the blue-green and red wavelengths; the ultraviolet (UV) is included in the interval most similar to the UV attenuation scales. Both intervals begin at the same shallowest depth, but the blue-green interval is allowed to extend deeper if the linearity in $\left[L_{\mathrm{u}}(z, \lambda)\right]$, as determined statistically, is thereby improved. The negative value of the slope of the regression yields the diffuse attenuation coefficient, $K_{\mathrm{d}}(\lambda)$, which is used to extrapolate the fitted portion of the $E_{\mathrm{d}}$ profile through the near-surface layer to null depth, $z=0^{-}$.

Fluctuations caused by surface waves and so-called lens effects prevent accurate measurements of $E_{\mathrm{d}}(\lambda)$ close to the surface (Zaneveld et al., 2001). A value just below the surface (at null depth $z=0^{-}$) can be compared to that measured contemporaneously above the surface (at $z=0^{+}$) with a separate solar reference using

$E_{\mathrm{d}}\left(0^{-}, \lambda\right)=0.97 E_{\mathrm{d}}\left(0^{+}, \lambda\right)$,

where the constant 0.97 represents the applicable air-sea transmittance, Fresnel reflectances, and the irradiance reflectance $\left(E_{\mathrm{u}} / E_{\mathrm{d}}\right)$, and is determined to an accuracy better than $1 \%$ for solar elevations above $30^{\circ}$ and low-to-moderate wind speeds. The distribution of $E_{\mathrm{d}}$ measurements at any depth $\mathrm{z}$ influenced by wave-focusing effects does not follow a Gaussian distribution, so linear fitting of $E_{\mathrm{d}}$ in a nearsurface layer is poorly constrained, especially if the number of samples is small. The application of (2) to the fitting process establishes a boundary condition or constraint for the fit (Hooker and Brown, 2013).

The appropriateness of the $E_{\mathrm{d}}$ extrapolation interval, initially established by $z_{1}$ and $z_{2}$, is evaluated by determining if (2) is satisfied to within approximately the uncertainty of the calibrations (a few percent); if not, $z_{1}$ and $z_{2}$ are redetermined - while keeping the selected depths within the shallowest homogeneous layer possible - until the disagreement is minimized (usually to within $5 \%$ ). The linear decay of $\ln [\aleph(z, \lambda)]$ for all light parameters in the chosen near-surface layer is then evaluated, and if linearity is acceptable, the entire process is repeated on a cast-by-cast basis. Subsurface primary quantities at null depth, $\aleph\left(0^{-}, \lambda\right)$, are obtained from the slope and intercept given by the least-squares linear regression of $\ln [\aleph(z, \lambda)]$ versus $z$ within the extrapolation interval specified by $z_{1}$ and $z_{2}$.

The processing uses two extrapolation intervals, one for the UV-green and one for the red-NIR. Both intervals start at the same depth, but the UV-green is allowed to extend deeper, because the attenuation is frequently less, as long as that part of the water column that is involved remains homogeneous. The average extrapolation intervals are in the top $1.5-3 \mathrm{~m}$ of the water column for the UV-green, and in the top 1-2 $\mathrm{m}$ for the red and near infrared.

The water-leaving radiance is obtained directly from

$L_{\mathrm{w}}(\lambda)=0.54 L_{\mathrm{u}}\left(0^{-}, \lambda\right)$,

where the constant 0.54 accurately accounts for the partial reflection and transmission of the upwelled radiance through the sea surface, as confirmed by Mobley (1999). To account for the aforementioned dependence of $L_{\mathrm{w}}$ on the solar flux, which is a function of atmospheric conditions and time of day, $L_{\mathrm{w}}$ is normalized by the (average) global solar irradiance measured during the time interval corresponding to $z_{1}$ and $z_{2}$ :

$R_{\mathrm{rS}}(\lambda)=\frac{L_{\mathrm{w}}(\lambda)}{E_{\mathrm{d}}\left(0^{+}, \lambda\right)}$

where $R_{\mathrm{rs}}$ is the remote sensing reflectance. Normalized variables are the primary input parameters for inverting TChl $a$ concentration from in situ optical measurements as part of 
the "OC" class of algorithms (O'Reilly et al., 1998), which means they are central variables for validation exercises.

An additional refinement includes the bidirectional nature of the upwelled radiance field, which is to a first approximation dependent on the solar zenith angle. An early attempt to account for the bidirectionality of $L_{\mathrm{w}}$ by Gordon and Clark (1981), following Austin (1974), defined a normalized water-leaving radiance, $\left[L_{\mathrm{w}}(\lambda)\right]_{\mathrm{N}}$, as the hypothetical water-leaving radiance that would be measured in the absence of any atmospheric loss with a zenith Sun at the mean Earth-Sun distance. The latter is accomplished by adjusting $R_{\mathrm{rs}}(\lambda)$ with the time-dependent mean extraterrestrial solar irradiance, $F_{0}$ (ignoring all dependencies except wavelength for brevity):

$\left[L_{\mathrm{w}}(\lambda)\right]_{\mathrm{N}}=F_{0}(\lambda) R_{\mathrm{rs}}(\lambda)$,

where $F_{0}(\lambda)$ is usually formulated to depend on the day of the year and is derived from look-up tables (Thuillier et al., 2003). An additional correction for a so-called exact normalized water-leaving radiance is required for satellite and seatruth matchups (Mueller and Morel, 2003), but that level of completeness is not needed here.

The solar zenith angle for the Malina data set ranged from 53 to $79^{\circ}$ and had an average value of $62^{\circ}$, which is within or close to the $75^{\circ}$ threshold for some of the data processing corrections, e.g., computing the bidirectional correction for the exact form of the normalized water-leaving radiance. The vast majority of the Malina data were collected under overcast (i.e., diffuse) conditions, wherein the Fresnel reflectance does not vary appreciably (i.e., literature values are to within $2 \%$ of the value used in the data processing scheme). In addition, the majority of the data were collected in quiescent waters from a small vessel, so wave-focusing effects were minimized. Under these conditions the convergence between the extrapolated in-water $E_{\mathrm{d}}\left(0^{-}\right)$values taken through the air-sea interface for comparison with $E_{\mathrm{d}}\left(0^{+}\right)$(per the bounding condition used in the processor) is easily satisfied with minimum manipulation of the extrapolation interval (assuming the interval is defined in a homogenous layer, which is required).

When needed, the irradiance reflectance $R\left(=E_{\mathrm{u}} / E_{\mathrm{d}}\right)$ is derived from $R_{\mathrm{rs}}$ following

$R(\lambda)=\frac{Q_{\mathrm{n}} R_{\mathrm{rs}}}{\Re}$,

where the nadir $Q$ factor $\left(Q_{\mathrm{n}}\right)$ is a function of $\mathrm{Chl} a$ and the Sun zenith angle (Morel and Gentili, 1993) and $\Re$ includes all reflection and refraction effects at the air-sea interface (Morel and Gentili, 1996).

\subsection{Inherent optical properties and geophysical quantities}

\subsubsection{Absorption by colored dissolved organic matter (CDOM)}

The light absorbance of colored dissolved organic matter $(\mathrm{CDOM})$ was measured using an UltraPath liquid waveguide system manufactured by World Precision Instruments, Inc. (Sarasota, Florida). The detailed methodology is described in Matsuoka et al. (2012), so only a brief summary is presented here. Water samples were collected from a Niskin bottle or a clean plastic container (for surface samples) into prerinsed glass bottles covered with aluminium foil. Water samples were immediately filtered after sampling using $0.2 \mu \mathrm{m}$ GHP filters (Acrodisc Inc.) pre-rinsed with $200 \mathrm{~mL}$ of pure water. Absorbance spectra of the filtered waters were then measured at sea from 200 to $735 \mathrm{~nm}$ with $1 \mathrm{~nm}$ increments with reference to a salt solution (the salinity of the reference was adjusted to that of the sample, to within 2 salinity units), prepared with pure water and granular $\mathrm{NaCl}$ pre-combusted in an oven (at $450^{\circ} \mathrm{C}$ for $4 \mathrm{~h}$ ).

An UltraPath allows four optical path lengths ranging from 0.05 to $2 \mathrm{~m}$ (i.e., $0.05,0.1,0.5$, and $2 \mathrm{~m}$ ) to be selected. In most cases, a $2 \mathrm{~m}$ path length was used, except for coastal waters at the Mackenzie River mouth, where a $0.1 \mathrm{~m}$ path length was used. The absorption coefficient of CDOM, $a_{\mathrm{CDOM}}(\lambda)$, in units per meter, was calculated from the measured values of absorbance $(A)$, or optical density, as follows:

$a_{\mathrm{CDOM}}(\lambda)=2.303 \frac{A(\lambda)-\bar{A}(685)}{1}$,

where 2.303 is a factor for converting from natural to base 10 logarithms, 1 is the optical path length (in meters), and for each absorbance spectrum the $5 \mathrm{~nm}$ average of the measured values of $A(\lambda)$ centered around $685 \mathrm{~nm}, \bar{A}(685)$, was assumed to be zero and the $A(\lambda)$ spectrum was shifted accordingly (Pegau et al., 1997; Babin et al., 2003).

\subsubsection{Total chlorophyll $a$ (TChl $a)$}

Seawater filtration through $25 \mathrm{~mm}$ GF/F filters under low vacuum was used to collect particulate matter for phytoplankton pigment analyses. Filters were flash-frozen in liquid nitrogen and kept at $-80^{\circ} \mathrm{C}$ until analyses. The pigment concentrations were determined by high-performance liquid chromatography (HPLC), following Van Heukelem and Thomas (2001) as modified by Ras et al. (2008). Total $\mathrm{Chl} a$ is calculated here as the sum of Chlorophyll $a$, divinyl Chlorophyll $a$ and Chlorophillide $a$, as recommended by the National Aeronautics and Space Administration (NASA) protocol for ocean color algorithm development and validation (Hooker et al., 2005). 


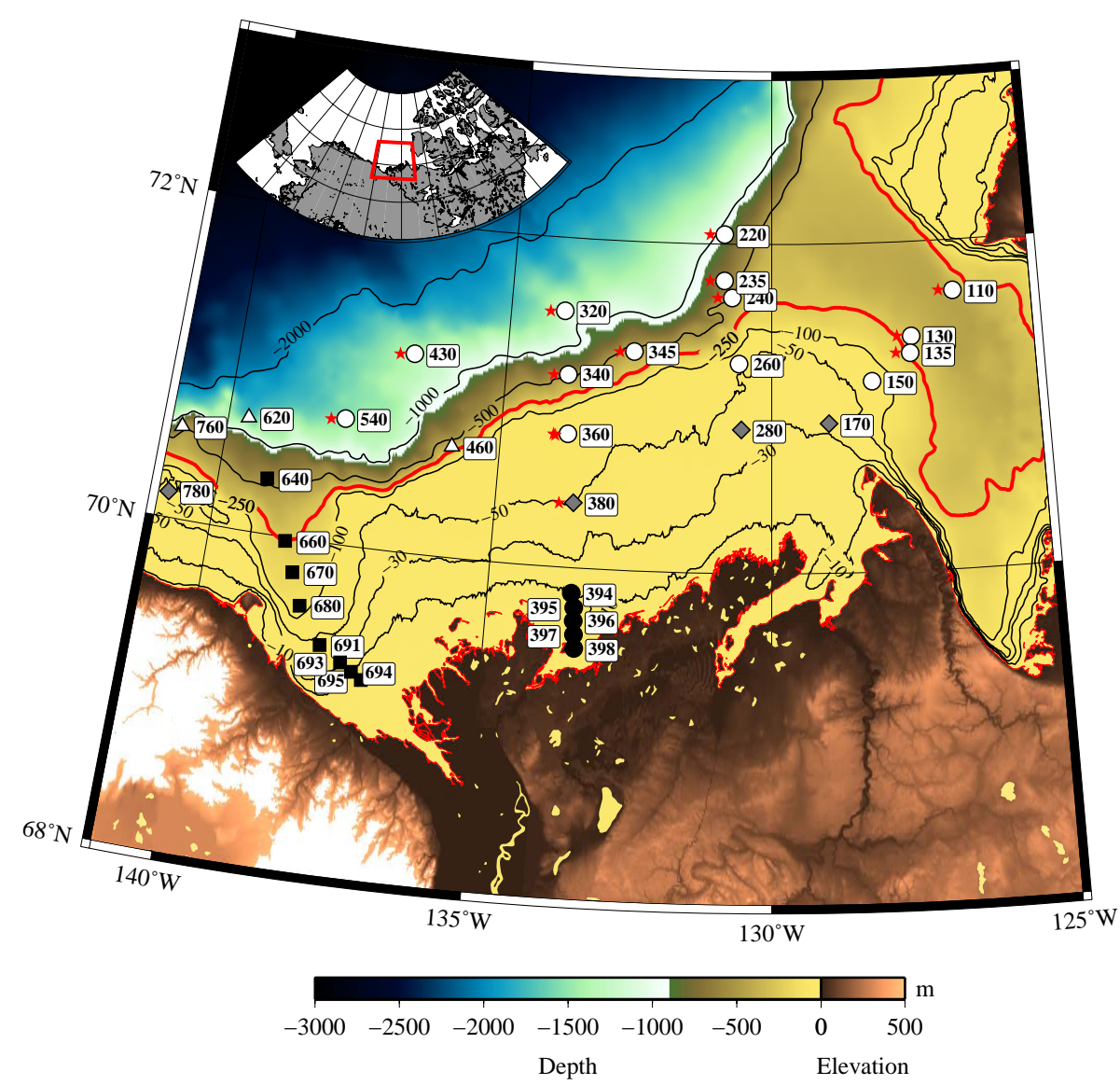

Fig. 1. Map of the sampling area of the Malina Leg2b cruise (31 July to 29 August 2009). The meaning of symbols for stations is given in legend of Fig. 4.

\subsubsection{Suspended particulate matter (SPM)}

Suspended particle matter (SPM) concentrations were measured following Doxaran et al. (2012). Triplicate low vacuum (Van der Linde, 1998) filtrations of known volumes ( $V$, in $\mathrm{L})$ of seawater $(0.2$ to $6 \mathrm{~L}$, depending on turbidity) were performed through pre-ashed $\left(1 \mathrm{~h}\right.$ at $\left.450{ }^{\circ} \mathrm{C}\right)$ and pre-weighed (M0 in mg) $25 \mathrm{~mm}$ glass-fibre filters (Whatman, GF/F $0.7 \mu \mathrm{m}$ nominal pore size). The filters were rinsed with Milli-Q water, dried for $12 \mathrm{~h}$ at $60^{\circ} \mathrm{C}$, and finally stored at $-80^{\circ} \mathrm{C}$ in clean Petri slides covered with aluminium foil. Back in the laboratory, filters were dried again and then weighed (M1), and SPM was calculated by dividing the difference between M0 and M1 by the volume filtered.

\section{Results}

\subsection{Sampling area}

The map in Fig. 1 shows the location and bathymetry of the sampling area of the Malina program in the Beaufort Sea (Canadian Arctic), and displays sampling stations occupied during Leg2b of the cruise. These stations were organized along seven approximately north-south transects, the easternmost being identified as transect 100 , followed by 200 and so on when progressing to the west. Only one or two stations were occupied on transects 400, 500 and 700. Overall, twenty-one (21) stations were located on the continental shelf (bottom depth $<250 \mathrm{~m}$; delineated by the thick red curve in Fig. 1), among which the two river transects had depths $<10 \mathrm{~m}$ (stations 691-696 for what will be referred to as the western Mackenzie transect and stations 394-398 for the eastern Mackenzie transect). The other 15 stations are at open-ocean locations, with water depths greater than $250 \mathrm{~m}$, and reaching a maximum of $1670 \mathrm{~m}$ at station 620 . The deepest part of the Beaufort Basin (depths $>2000 \mathrm{~m}$ ) was covered by a thick multi-year icecap, and it was not sampled during Malina (see Fig. 1 in Bélanger et al., 2013).

Sampling was constrained by the presence of ice in the southern Beaufort Sea and by the overall cruise objectives, which implied collecting data both as close as possible to the Mackenzie River outflows and as far offshore as possible in the deep part of the Beaufort Sea. The different symbols in Fig. 1 mostly reflect where the stations are located 
with respect to the coast and the shelf, with black symbols (squares and circles) for the two river transects and open symbols for open-ocean stations. Intermediate coastal locations are depicted in gray. This purely geographical split of stations actually also corresponds to well-identified clusters of stations based on optical criteria (see later on). Red stars in Fig. 1 indicate the stations with the clearest surface waters, i.e., $0.024 \mathrm{~m}^{-1}<K_{\mathrm{d}}(443)<0.1 \mathrm{~m}^{-1}$. The lower bound corresponds to what the Morel and Maritorena (2001) biooptical model would predict for a case-1 water with a Chl $a$ concentration of $0.05 \mathrm{mg} \mathrm{m}^{-3}$.

\subsection{The different light environments sampled during the cruise}

The combination of the sampling constraints described above with the characteristics of water masses and bottom topography led to the exploration of a large range of conditions in terms of water turbidity and optical complexity. This is illustrated in Fig. 2, which shows the exponential decrease of downward irradiance normalized to its value just below the sea surface, sorted as a function of the diffuse attenuation coefficient for downward irradiance at $443 \mathrm{~nm}, K_{\mathrm{d}}(443)$ (see Sect. 2.1 for determination of $K_{\mathrm{d}}$ ). The right part of the plot, for $K_{\mathrm{d}}(443)>\sim 0.6 \mathrm{~m}^{-1}$, corresponds to sampling in the two river transects (station numbers from 680 in the west Mackenzie transect and 394 to 398 for the east transect; see Fig. 1). At these very turbid stations, the one-percent light level $\left(z_{1 \%}\right)$ for $\lambda=443 \mathrm{~nm}$ is at depths from about 1 to $5 \mathrm{~m}$. At a few intermediate stations, where $\sim 0.3 \mathrm{~m}^{-1}<K_{\mathrm{d}}(443)$ $<\sim 0.6 \mathrm{~m}^{-1}$, this depth is of about $20-30 \mathrm{~m}$. For the clearest stations $\left(K_{\mathrm{d}}(443)<\sim 0.2 \mathrm{~m}^{-1}\right), z_{1} \%$ varies from about 50 to $70 \mathrm{~m}$. The data set is therefore essentially made, on the one hand, of clear waters of the deep Beaufort Basin and shelf waters with water depths greater than about $50 \mathrm{~m}$ (17 stations over a total of 36) and, on the other hand, of very turbid waters from the Mackenzie outflows (11 stations). Eight stations represent intermediate situations, some of them being classified as "coastal".

Four stations have been selected to illustrate in more detail the underwater light environments that were sampled during Malina Leg2b. The corresponding downward irradiance spectra at various depths, normalized to the maximum value found in the shallowest spectrum, are displayed in Fig. 3. They show, as expected, the progressive shift of the maximum transmission from the blue wavelengths $(\lambda \sim 490 \mathrm{~nm})$ for the clear station (Fig. 3b) to the green for mesotrophic stations (Fig. 3b), and to the green and red for the highly turbid stations of the river transect (Fig. 3c and d). The underwater environment at these turbid stations is nearly depleted of $\mathrm{UV}$ radiation, which is absorbed within the first meter (less than $1 \%$ radiation for $\lambda<400 \mathrm{~nm}$ at a depth of $1 \mathrm{~m}$ ). The $E_{\mathrm{d}}$ peak due to $\mathrm{Chl} a$ fluorescence appears at the depth of the deep chlorophyll maximum for the clearest station, i.e., at about $50 \mathrm{~m}$ (Fig. 3a), and, to lesser extent, at station 170

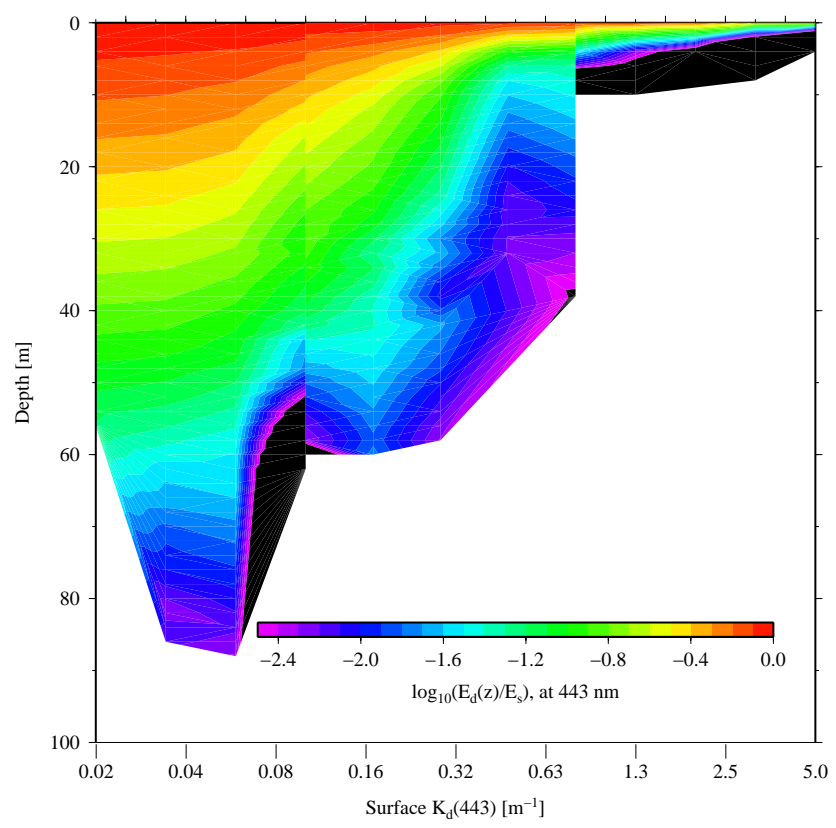

Fig. 2. Vertical profiles of the decimal logarithm of the downward irradiance normalized to its value just below the sea surface. Data are sorted as a function of the $K_{\mathrm{d}}(443)$ value for the surface layer. Discontinuities are due to sorting the profiles as a function of the surface $K_{\mathrm{d}}$ only.

located near Cape Bathurst where moderate $\mathrm{Chl} a$ concentrations were observed (i.e., 0.5 to $1.7 \mathrm{mg} \mathrm{m}^{-3}$ ) (Fig. 3b). At other stations, there is either not enough Chl $a$ or too much of the light is absorbed in the blue-green by CDOM to produce a significant fluorescence signal.

The large range of optical characteristics encountered during Malina Leg2b can actually be depicted by the relationship between the diffuse attenuation coefficient for downward irradiance $\left(K_{\mathrm{d}}\right)$ at the two extremes of the spectrum sampled here, i.e., at 320 and $780 \mathrm{~nm}$. The rationale for using these two values as a classification tool is fully explored in the companion paper of this study (Hooker et al., 2013). Here it is used to show how the data set is distributed among different light regimes, and to identify stations clusters and assign them symbols that will be used from now on in this study to facilitate data interpretation. When plotting $K_{\mathrm{d}}(780)$ as a function of $K_{\mathrm{d}}(320)$ (Fig. 4), a first group of stations clearly shows up with low $K_{\mathrm{d}}$ values for both wavelengths. They correspond to the more offshore stations, and they will be identified by open circles. A number of stations that would intuitively fall in the same category if they were classified on the basis of their geographical proximity with open-ocean stations actually separately appear in Fig. 4. They show low $K_{\mathrm{d}}(320)$ but moderate $K_{\mathrm{d}}(780)$ values. They also correspond to clear waters but were characterized by the presence of an ice floe close to where the radiometry profiles were performed. These "ice-edge" stations are identified 

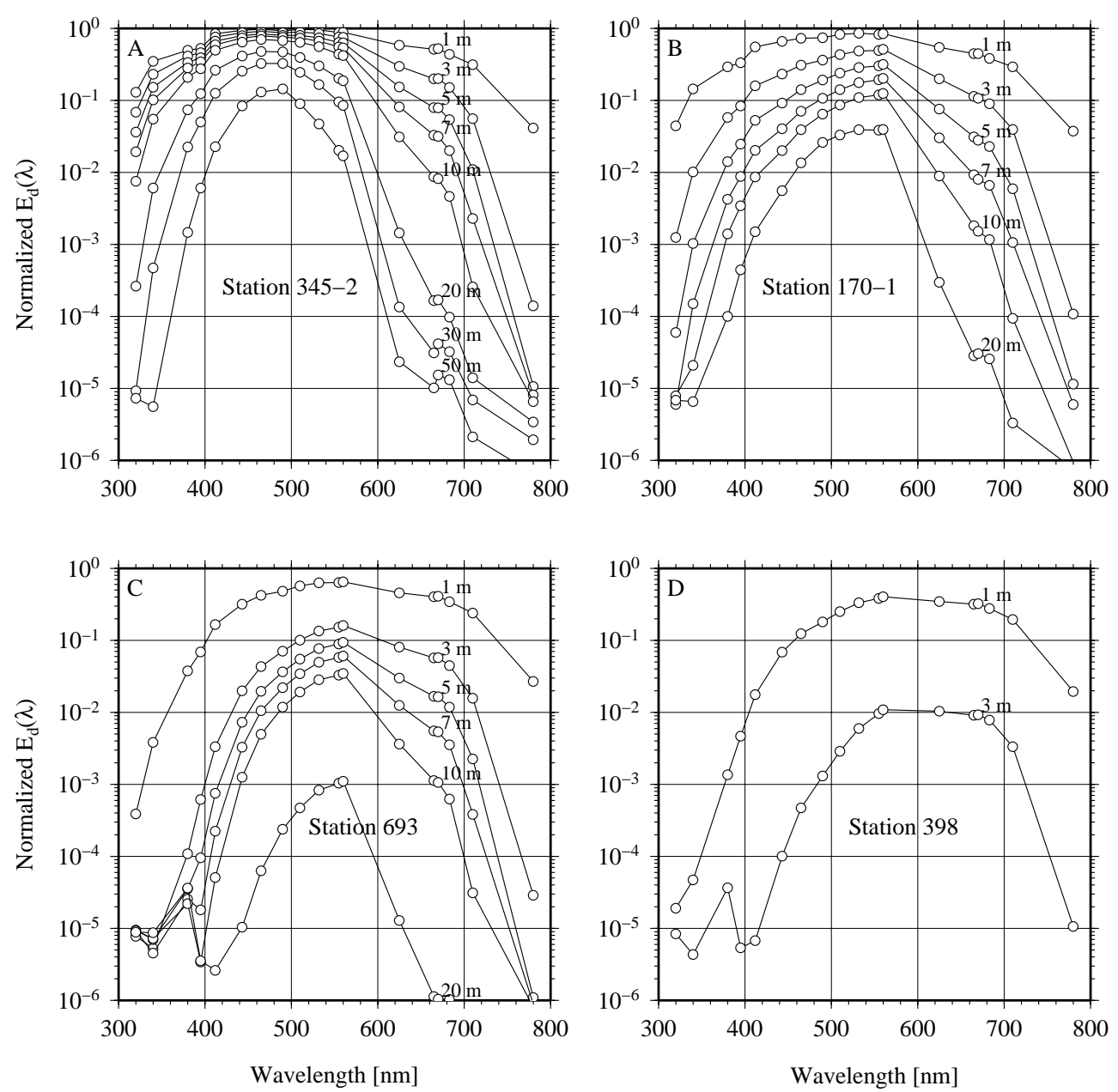

Fig. 3. Example spectra of the downward irradiance at various depths and four stations as indicated. Values are normalized to the maximum $E_{\mathrm{d}}$ found just below the sea surface.

by open triangles. Most of the stations corresponding to the two river transects have $K_{\mathrm{d}}(320)$ values greater than $3 \mathrm{~m}^{-1}$. Therefore they very clearly separate from other stations (dark circles and squares). Stations of the northern part of the western Mackenzie transect (640 to 680) represent an intermediate situation (cluster of black squares for $K_{\mathrm{d}}(320) \sim 2 \mathrm{~m}^{-1}$ and $K_{\mathrm{d}}(780) \sim 3 \mathrm{~m}^{-1}$ ). Gray diamonds identify the coastal stations.

\subsection{Case-1/case-2 water classification}

The irradiance reflectance at $560 \mathrm{~nm}, R(560)$, is plotted as a function of the $\mathrm{Chl} a$ concentration, Chl, in Fig. 5a. The theoretical maximum value of $R(560)$ above which waters would belong to the sediment-dominated case- 2 category (Morel and Prieur, 1977) has been computed from Chl $a$ following Morel and Bélanger (2006) (continuous curve in Fig. 5a). Clearly, a large part of the Malina Leg2b data set is made of so-called case-2-S waters. As expected, these waters essentially correspond to the two river transects and the coastal stations, where water turbidity was high. A few of the open-ocean stations would also fall in the same category, at least with the criterion used here. It is known, however, that the theoretical threshold poorly performs for low Chl $a$ and does not distinguish yellow-substance-dominated case- 2 waters (Morel and Bélanger, 2006). The ice-edge stations all fall below the theoretical line, which indicates that closeness of an ice floe would not enhance scattering in the green part of the spectrum, which is the parameter that essentially drives the theoretical threshold used here. Another possibility is that enhanced scattering is counterbalanced by enhanced absorption in these particular situations (see Sect. 3.3.2 in Bélanger et al., 2013).

Another look at the case-1/case-2 classification is given in Fig. $5 \mathrm{~b}$, where the ratio of remote sensing reflectances at 412 and $443, R_{\mathrm{rs}}(412) / R_{\mathrm{rs}}(443)$, is plotted as a function of the $R_{\mathrm{rs}}(555) / R_{\mathrm{rs}}(490)$ ratio (as in Lee and $\mathrm{Hu}, 2006$; see also Morel and Gentili, 2009). A monotonic relationship exists between both ratios when they are determined from a case-1 water bio-optical model. Lee and Hu (2006) derived 


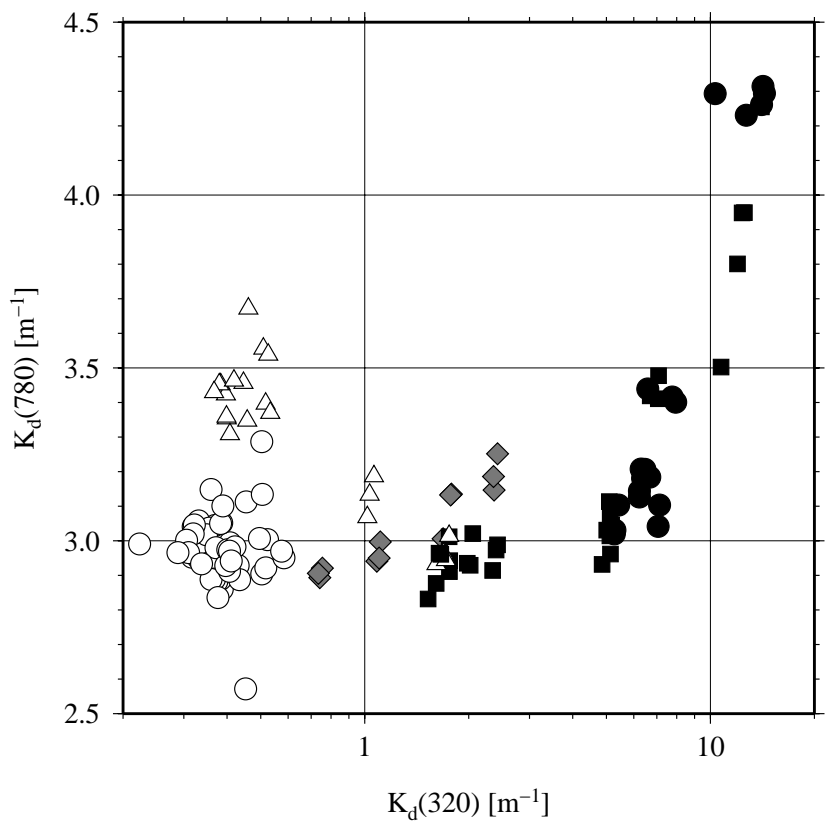

Fig. 4. $K_{\mathrm{d}}(780)$ as a function of $K_{\mathrm{d}}(320)$. The grouping of points shown here was used to group stations into different clusters as follows: offshore clear-water stations (open circles), coastal stations (gray diamonds), the western Mackenzie transect (black squares), the eastern Mackenzie transect (black circles), and ice-edge stations (open triangles).

such a relationship from the Chl-based bio-optical model of Morel and Maritorena (2001) (MM01). The corresponding curve is superimposed on the Malina data points in Fig. 5b. Case-1 water stations should be distributed within $\pm 10 \%$ of this theoretical line (see Fig. 1 in Lee and Hu, 2006), which is not the case here. The entire data set, on the contrary, falls well below the average curve and outside of the $\pm 10 \%$ variability, which indicates a much lower than expected $R_{\mathrm{rs}}(412) / R_{\mathrm{rs}}(443)$ ratio. This is a clear indication of an excess of absorption by CDOM.

Therefore, although the more offshore stations of Malina Leg2b can be ascribed to the case- 1 water category when looking at a criterion essentially based on scattering (Fig. 5a), none of the stations would belong to this category when the classification is based on the relative proportion of CDOM with respect to scattering (or $\mathrm{Chl} a$ ).

\subsection{Spectral characteristics}

A few stations have been selected as exemplary of spectral shapes present in our data set. The corresponding spectra of normalized $R_{\mathrm{rs}}$ and $K_{\mathrm{d}}$ 's are displayed in Fig. $6 \mathrm{a}$ and b, respectively, for stations 394-398 (east transect), 380 (coastal), 320,340 and 360 (open-ocean clear waters), and 460 and 760 (ice-edge stations). For the river stations, extremely low $R_{\mathrm{rs}}$ in the UV bands, around $5 \times 10^{-5} \mathrm{sr}^{-1}$, combined with large values in the red part of the spectrum (about $2 \times 10^{-2} \mathrm{sr}^{-1}$ )
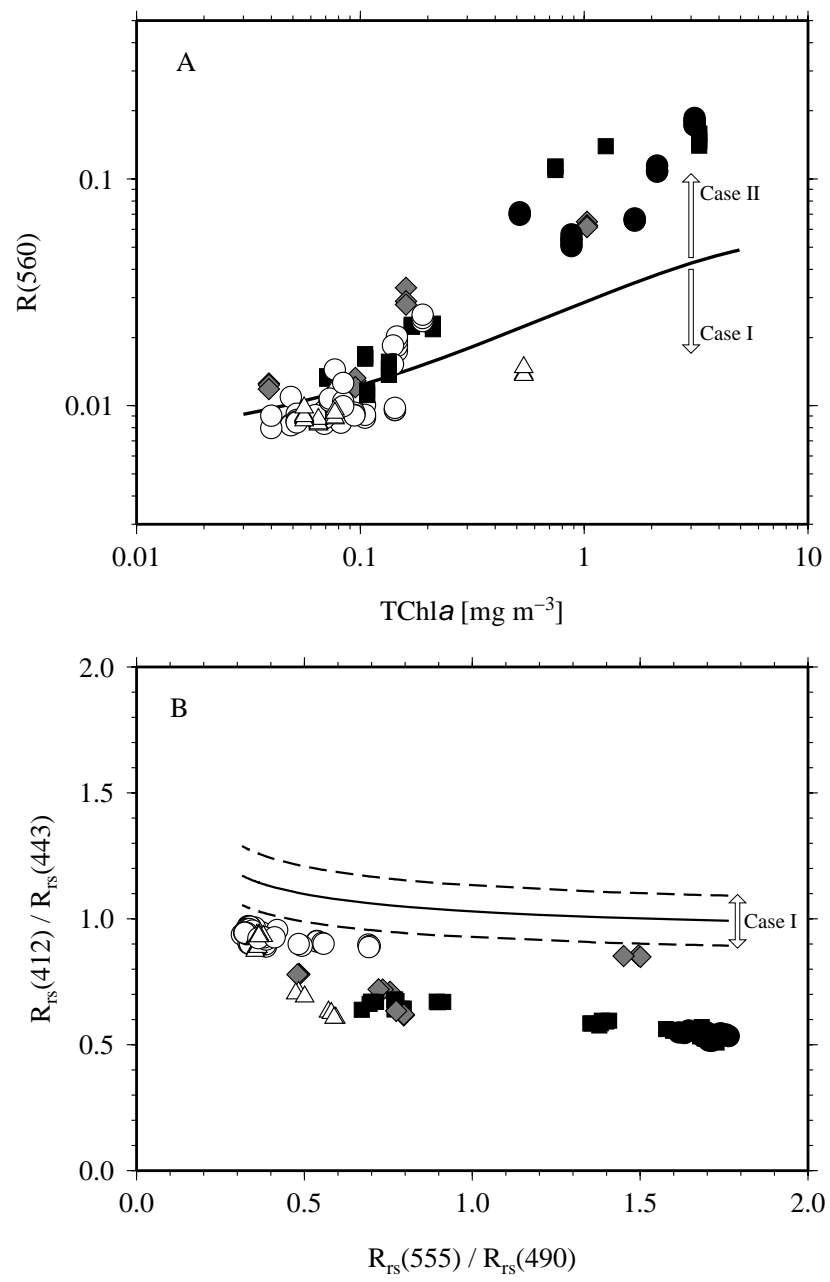

Fig. 5. (A) Irradiance reflectance at $560 \mathrm{~nm}, R(560)$, as a function of the Chl $a$ concentration. The curve corresponds to the theoretical limit between case- 1 and case- 2 waters, computed from Chl $a$ following Morel and Bélanger (2006). (B) $R_{\mathrm{rs}}(412) / R_{\mathrm{rs}}(443)$ as a function of $R_{\mathrm{rs}}(555) / R_{\mathrm{rs}}(490)$. The solid line corresponds to Eq. (2a) in Lee and $\mathrm{Hu}$ (2006), and the dashed curves to $\pm 10 \%$ around this line.

make $R_{\mathrm{rs}}$ varying over about three decades. The $R_{\mathrm{rs}}$ values for open-ocean and coastal stations vary over slightly more than two decades. The $K_{\mathrm{d}}$ values in the UV bands can be as high as $20 \mathrm{~m}^{-1}$ in the innermost part of the Mackenzie River mouth. In the visible spectral domain, the lowest values are of about $0.035 \mathrm{~m}^{-1}$. They expectedly correspond to the blue bands ( $490 \mathrm{~nm}$ in particular) of the open-ocean stations.

The case-1/case- 2 delineation examined in Fig. 5 is insufficient to fully characterize the optical regimes. It cannot, in particular, indicate whether or not the waters classified here as case-1 have similar spectral characteristics as case- 1 waters of other oceanic areas. It has already been shown that optical properties of low-chlorophyll clear waters can significantly vary at a given Chl $a$ concentration (Morel et al., 2007a; Brown et al., 2008). Therefore, the spectral shape of 

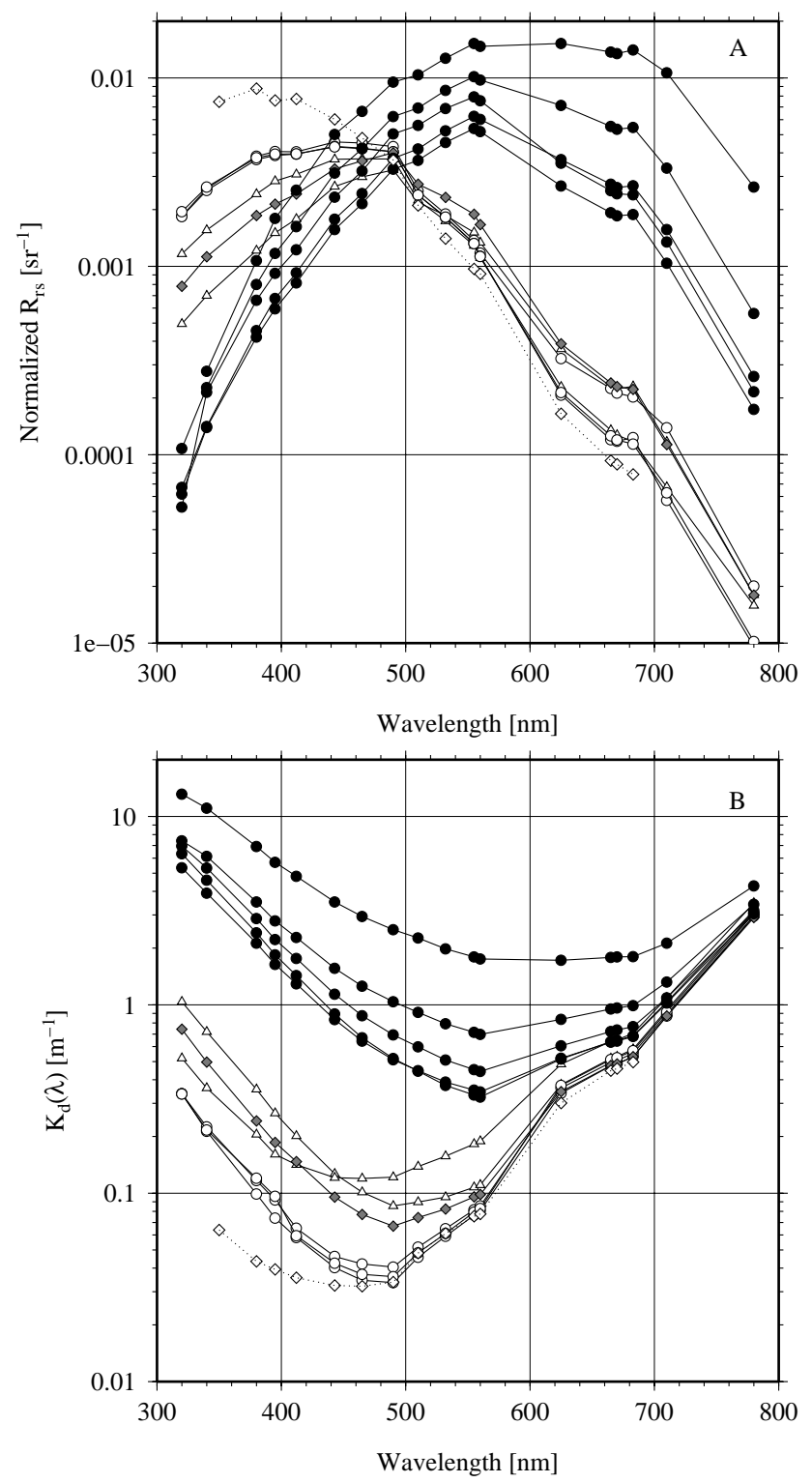

Fig. 6. Example $R_{\mathrm{rs}}(\mathbf{A})$ and $K_{\mathrm{d}}(\mathbf{B})$ spectra, for stations 320,340 and 360 (open waters), 235 and 460 (ice edge), 380 (coastal), and 394-398 (eastern Mackenzie transect). The open diamonds show modeled values from Morel and Maritorena (2001).

offshore stations in the Beaufort Sea have been compared to the prediction of the MM01 bio-optical model, in order to see how this particular sea behaves with respect to the mean conditions encountered in the world ocean. The model was fed with the average Chl $a$ concentration and Sun zenith angle of the 3 stations shown in Fig. 6 (Chl $a=0.05 \mathrm{mg} \mathrm{m}^{-3}$, $\theta_{\mathrm{s}}=62^{\circ}$ ). The resulting $R_{\mathrm{rs}}$ and $K_{\mathrm{d}}$ are displayed in Fig. $6 \mathrm{a}$ and $\mathrm{b}$ as open diamonds connected by a dotted line (note that the spectral range of the model is limited to $350-700 \mathrm{~nm}$ ). They show a close coincidence with the measured spectra for all spectral bands from 490 to $700 \mathrm{~nm}$, but a much higher
$R_{\mathrm{rs}}$ and much lower $K_{\mathrm{d}}$ in the near UV and blue parts of the spectrum than what was measured in the Beaufort Sea during Malina Leg2b (by about $\pm 50 \%$ at $443 \mathrm{~nm}$, and by a factor of about 2 at $412 \mathrm{~nm}$, for instance). What is referred to as open-ocean clear water here for the Beaufort Sea is actually much less blue than what can be found in other lowchlorophyll waters around the world. A similar depression of $R_{\mathrm{rs}}$ below $450 \mathrm{~nm}$ has been reported for the Beaufort Sea by previous authors (Wang and Cota, 2003; Matsuoka et al., 2007; Bélanger et al., 2007). A higher absorption by CDOM at a given $\mathrm{Chl} a$ concentration is likely responsible for this difference. This can be illustrated by computing the $\Phi$ factor from Morel and Gentili (2009), which expresses the excess or deficit in CDOM absorption as compared to what the Morel and Maritorena (2001) model would predict for a given Chl $a$ concentration. With a ratio $R(412) / R(443)$ of about 0.95 and a ratio $R(490) / R(555)$ of about 3.5 , as derived from the spectra shown in Fig. 6, and for Chl $a=0.05 \mathrm{mg} \mathrm{m}^{-3}$, the $\Phi$ factor would be close to 5 (see Fig. 2b in Morel and Gentili, 2009). This is a clear indication that CDOM absorption is much higher in the clear waters of the Beaufort Sea than it is elsewhere (see also Bélanger et al., 2013, and references therein).

The spectra identified by open triangles in Fig. 6 correspond to two of the ice-edge stations. The surface Chl $a$ concentration for these two stations is in the same range as for the three open-ocean stations also displayed in Fig. 6 (open circles), namely values from 0.035 to $0.05 \mathrm{mg}(\mathrm{Chl}) \mathrm{m}^{-3}$. Their $R_{\mathrm{rs}}$ spectra differ for wavelengths lower than $\sim 500 \mathrm{~nm}$, however, with lower values for the iceedge stations. A much more significant difference is observed for the $K_{\mathrm{d}}$ spectra, by at least a factor of two, and not only for blue bands but across the entire spectrum. The enhanced particulate absorption in the top $2 \mathrm{~m}$ of the water column identified by Bélanger et al. (2013) is likely responsible for this increase in $K_{\mathrm{d}}$. In addition, the spectral shapes of the two ice-edge $K_{\mathrm{d}}$ spectra are different, indicating that the proximity of ice does not always lead to the same perturbation of optical properties. It may depend on the proximity of the ice edge, on the thickness of the ice sheet, the mixing conditions prior to measurement and on the chemical composition of the material that is released in the water when ice melts.

\subsection{Bio-optical relationships}

Radiometry measurements are not only used for characterization of the underwater light field. They are also largely used as inputs to bio-optical models aiming at quantifying geophysical parameters such as the $\mathrm{Chl} a$ concentration. We have accordingly examined whether existing bio-optical models that were developed for global ocean case- 1 waters could apply to the clear waters of the Beaufort Sea, either in their forward mode (i.e., deriving AOPs from $\mathrm{Chl} a$ ) or in their inverse forms to derive Chl $a$ from combinations - usually ratios - of AOPs. We used the MM01 as a typical model 

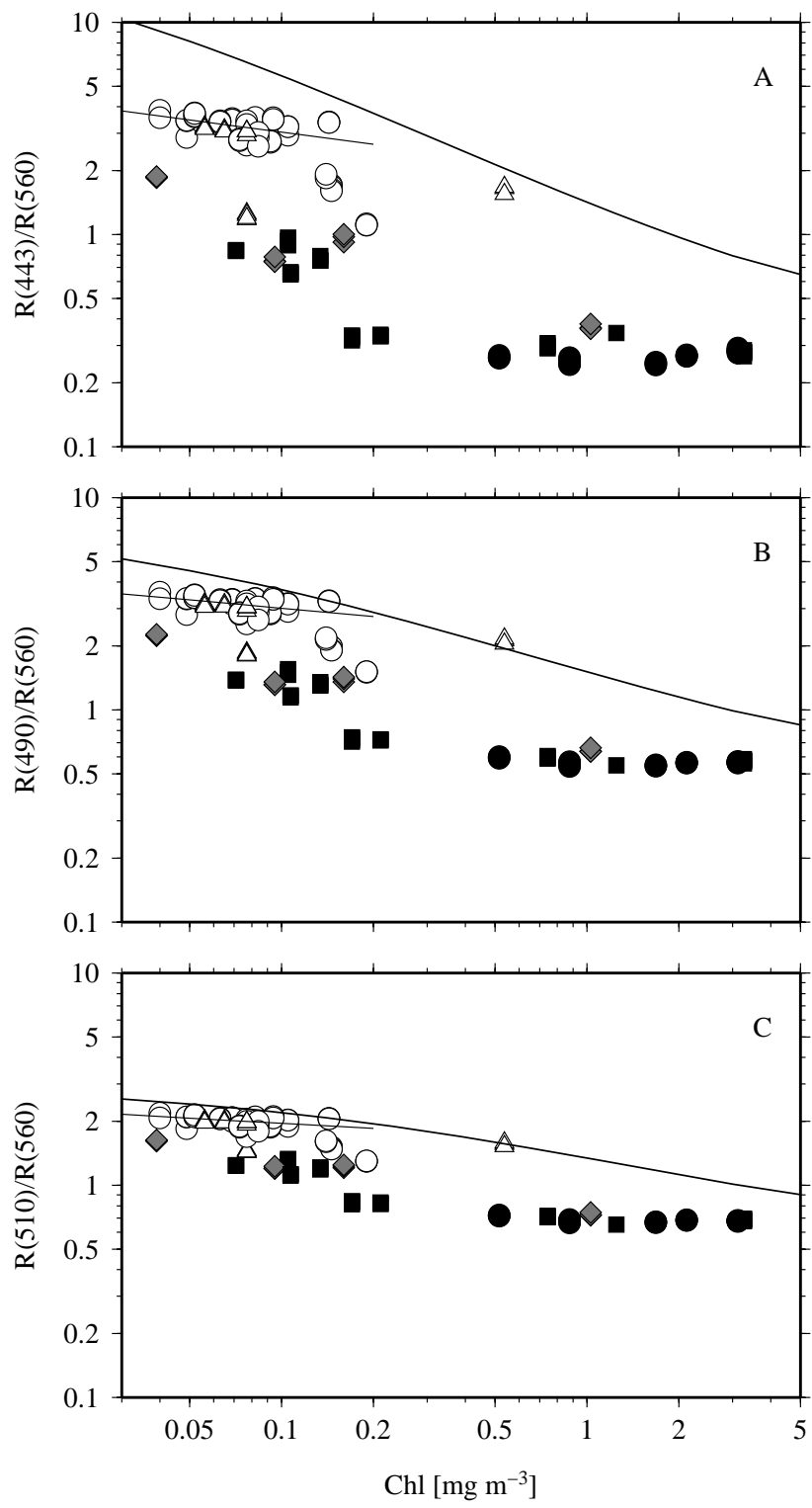

Fig. 7. Reflectance ratios for the wavelengths indicated, as a function of the Chl $a$ concentration. The thick solid curves show modeled values from Morel and Maritorena (2001). The thin solid curves are linear fits using the log-transformed data, for the clearwater stations only.

for case- 1 waters. The results are displayed on the three panels of Fig. 7, where three reflectance ratios are plotted as a function of Chl $a$, using either the field data (symbols) or the model (solid curve). None of the three reflectance ratios are appropriately reproduced by the model. The predicted average of the reflectance ratio is closer to the field values when using the 510-to-560 band ratio, but still with a significant overestimation $(15-20 \%)$. For the open-ocean stations the measured reflectance ratios are actually close to being insensitive to Chl $a$ when it is lower than about $0.15 \mathrm{mg} \mathrm{m}^{-3}$. This is illustrated by plotting the regression curve obtained on the log-transformed data, which shows a slope close to 0 (from -0.19 in Fig. 7 a to -0.08 in Fig. 7c). Clearly, the MM01 model cannot be used to predict reflectance ratios from $\mathrm{Chl} a$ in clear waters of the Beaufort Sea. Because the MM01 model is the basis for the OC4Me "satellite chl" maximumband-ratio algorithm (Morel et al., 2007b), using the latter to derive Chl $a$ from the reflectance ratios is also invalid, regardless of whether these ratios are obtained from field or satellite remote sensing observations (OC4Me was conceived to apply to observations from the European Medium Resolution Imaging Spectrometer - MERIS - ocean colour sensor). This comment can be actually extended to any similarly derived algorithm such as the OC4-like algorithms used by the NASA Sea-viewing Wide Field-of-view Sensor (SeaWiFS) and Moderate Resolution Imaging Spectroradiometer (MODIS) ocean color missions. As a consequence, accurately deriving $\mathrm{Chl} a$ in these clear waters from current ocean color remote sensing algorithms based on global data sets seems illusory. The $\mathrm{Chl}$ retrievals obtained via such algorithms are shown in Fig. 8, for the OC4Me (Morel et al., 2007) and GSM (Garver and Siegel, 1997; Maritorena et al., 2002) global algorithms, and for an algorithm locally tuned to the southeast Beaufort Sea waters (Ben Mustapha et al., 2012). The GSM algorithm performs better than the OC4Me because it allows for a varying CDOM component, whereas $\mathrm{OC} 4 \mathrm{Me}$ assumes proportionality between $\mathrm{Chl}$ and CDOM absorption. Both algorithms overestimate the field determinations, however. The local and empirical algorithm performs clearly better for $\mathrm{Chl}>\sim 0.2 \mathrm{mg} \mathrm{m}^{-3}$, yet it largely underestimates $\mathrm{Chl}$ in clear waters.

For the river transects, the reflectance ratios are also close to being insensitive to Chl $a$ when it is greater than about $0.2 \mathrm{mg} \mathrm{m}^{-3}$. This is rather expected, however, because optical properties at these stations are essentially under the influence of sediments. However, when the three panels in Fig. 7 are redrawn as a function of SPM instead of Chl $a$ (not shown), a similar grouping of stations appears, with thresholds of about 0.5 and $2 \mathrm{~g} \mathrm{~m}^{-3}$, respectively, below and above which the reflectance ratios little vary. Therefore, two optical regimes exist in the Beaufort Sea, inside which neither Chl $a$ nor SPM have a significant influence on the reflectance ratios, at least in the wavelength range examined here (440 to $560 \mathrm{~nm}$ ). So, deriving these quantities from AOP ratios (or other AOP combinations) probably necessitates embracing a broader spectral range.

Therefore, a thorough exploration of the relationships between AOPs or ratios of AOPs, and either IOPs or geophysical quantities such as particulate absorption, Chl $a$ and SPM, has been performed. Considering the high value we got for the $\Phi$ parameter (see above), absorption by CDOM has been considered as well. Because the range of optical regimes was large in the Leg2b data set, and because those waters that would belong to the case- 1 category when using a $\mathrm{Chl} a$ criterion actually behave differently from average models, the logic was to search for bio-optical relationships that would 

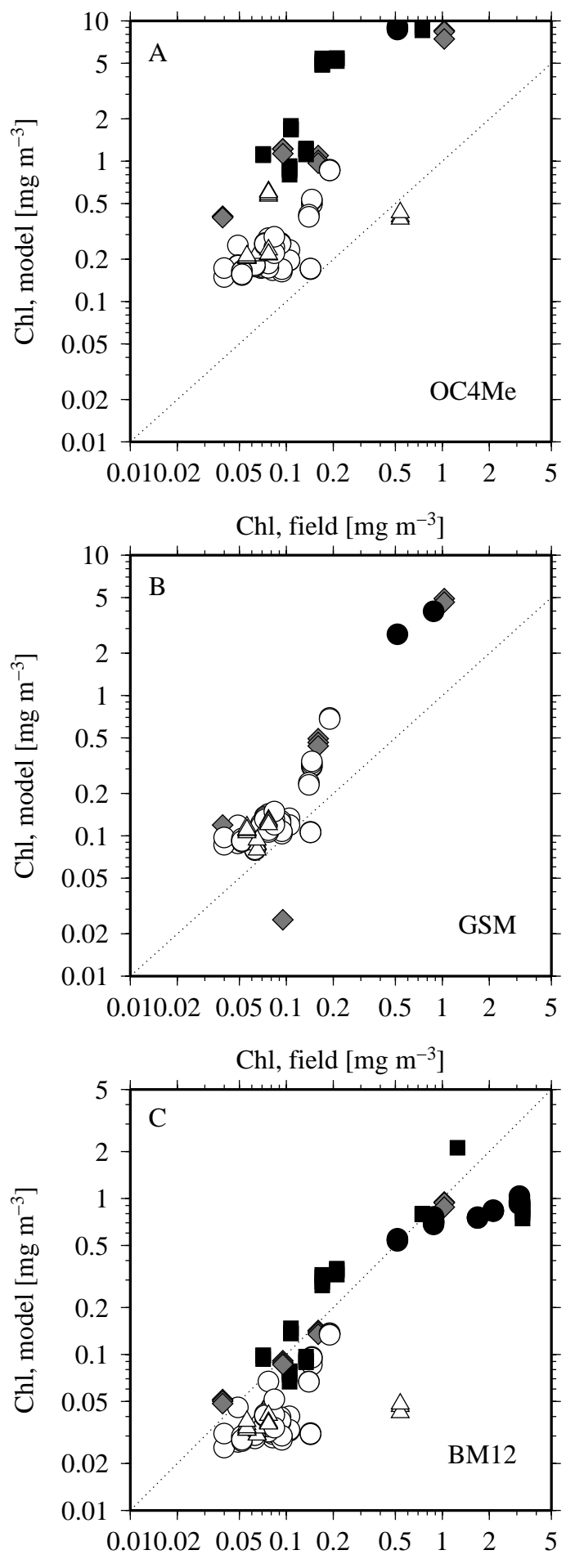

$\mathrm{Chl}$, field $\left[\mathrm{mg} \mathrm{m}^{-3}\right]$

Fig. 8. Chl concentrations retrieved from (A) OC4Me, (B) GSM and (C) Ben Mustapha et al. (2012) algorithms (see text), as a function of the $\mathrm{Chl}$ value determined from field samples.
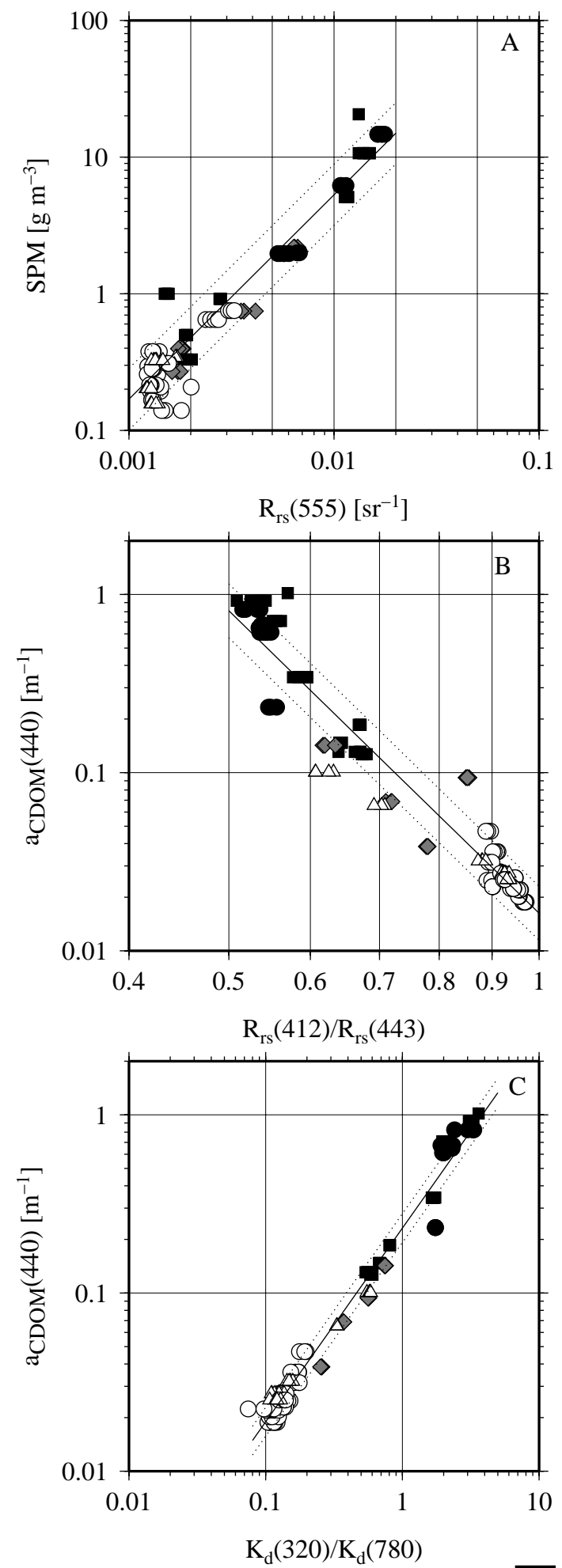

Fig. 9. Bio-optical relationships in the Malina Leg2b data set. Solid curves are regression fits on the log-transformed data, and the dotted curves show the RMSE around the regressions (A) $R_{\mathrm{rs}}(555) \mathrm{nm}$ as a function of SPM concentration, (B) ratio of $R_{\mathrm{rs}}(412)$ to $R_{\mathrm{rs}}(443)$ as a function of CDOM absorption at $440 \mathrm{~nm}$, and $(\mathbf{C})$ ratio of $K_{\mathrm{d}}(320)$ to $K_{\mathrm{d}}(780)$, as a function of CDOM absorption at $440 \mathrm{~nm}$. 

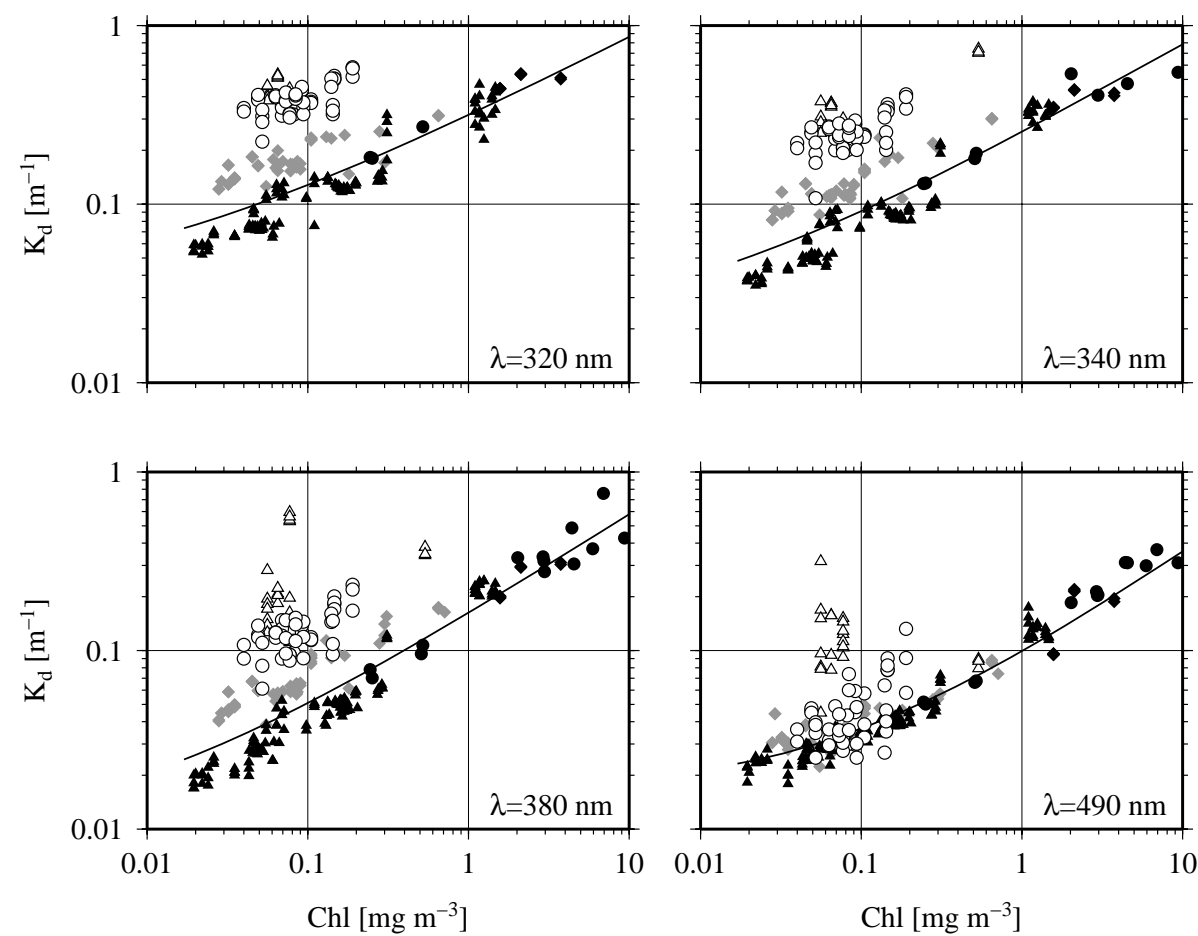

Fig. 10. $K_{\mathrm{d}}$ as a function of $\mathrm{Chl} a$, and for selected wavelengths as indicated (redrawn from Morel et al., 2007a, with addition of the data from Malina Leg2b). The open symbols are for the Malina Leg2b clear-water stations, the gray symbols for the Mediterranean Sea, and the black symbols for South Pacific data. The continuous black curve represents the MM01 prediction.

encompass the entire range of conditions encountered here, recognizing however that they could not be as accurate as specific relationships that would be established on more homogeneous subsets of data (e.g., only the clear-water stations). The latter might show a better predictive accuracy locally, yet they would have less general applicability.

This exercise revealed only three relationships valid for the entire data set and with an acceptable predictive accuracy. They emphasize the SPM concentration as a function of $R_{\mathrm{rs}}(555)$ (Fig. 9a), the CDOM absorption as a function of the $R_{\mathrm{rS}}(412) / R_{\mathrm{rs}}(443)$ ratio (Fig. 9b), and the CDOM absorption as a function of the $K_{\mathrm{d}}(320) / K_{\mathrm{d}}(780)$ ratio (Fig. 9c). The relative predictive skill of the linear regressions is given here as the root mean square error (RMSE) of the log-log regression. It is of about $50 \%$ for derivation of SPM directly from $R_{\mathrm{rS}}(555)$, of about $35 \%$ for derivation of $a_{\mathrm{CDOM}}(440)$ from the $R_{\mathrm{rs}}(412) / R_{\mathrm{rs}}(443)$ ratio, and of about $20 \%$ for derivation of aCDOM $(440)$ from the $K_{\mathrm{d}}(320) / K_{\mathrm{d}}(780)$ ratio. The latter provides an interesting opportunity to derive $a_{\mathrm{CDOM}}$ from field radiometry only, which is of great help, considering the difficulty in accurately measuring $a_{\mathrm{CDOM}}$ from field samples. This relationship would not, however, be of great help in a remote sensing context where spectral $K_{\mathrm{d}}$ values have to be determined indirectly from the sole quantity amenable to remote sensing, i.e., from spectral $R_{\mathrm{rs}}$. The less-accurate yet still-acceptable relationship shown in Fig. $9 \mathrm{~b}$ would have to be used from satellite $R_{\mathrm{rs}}$.

\section{Discussion}

It has been previously reported that the contribution of absorption by CDOM relative to other absorbing material, in particular phytoplankton, is higher in the absorption budget of Arctic waters than in other parts of the world ocean $(\mathrm{Pe}$ gau, 2002; Hill, 2008; Matsuoka et al., 2007, 2011; Bélanger et al., 2008, 2013; Ben Mustapha et al., 2012). Our results (Figs. 5, 6) confirm these specific characteristics, which were also quantified through the calculation of the $\Phi$ parameter from Morel and Gentili (2009). A synthetic view of the anomalously high attenuation in the UV and blue parts of the spectrum is provided in Fig. $10\left(K_{\mathrm{d}}\right.$ as a function of Chl $a$ ), where the $K_{\mathrm{d}}$ values for clear waters of Malina Leg2b (open symbols) are superimposed on values from other oceans (gray and black symbols), as redrawn from Morel et al. (2007a). This figure clearly shows that the Beaufort Sea clear waters have more absorption in the UV-blue for given low Chl $a$ levels than any other clear waters we have previously sampled (when "clear water" is defined with respect to $\mathrm{Chl} a$ ).

Among Malina's objectives is the determination of net primary production (NPP) in the Arctic from ocean color remote sensing observations. When doing so using so-called "satellite-chl" algorithms (Carr et al., 2006), one undergoes three main initial steps: (1) deriving surface Chl $a$ from spectral $R_{\mathrm{rs}}$ (O'Reilly et al., 1998; Morel et al., 2007b), 


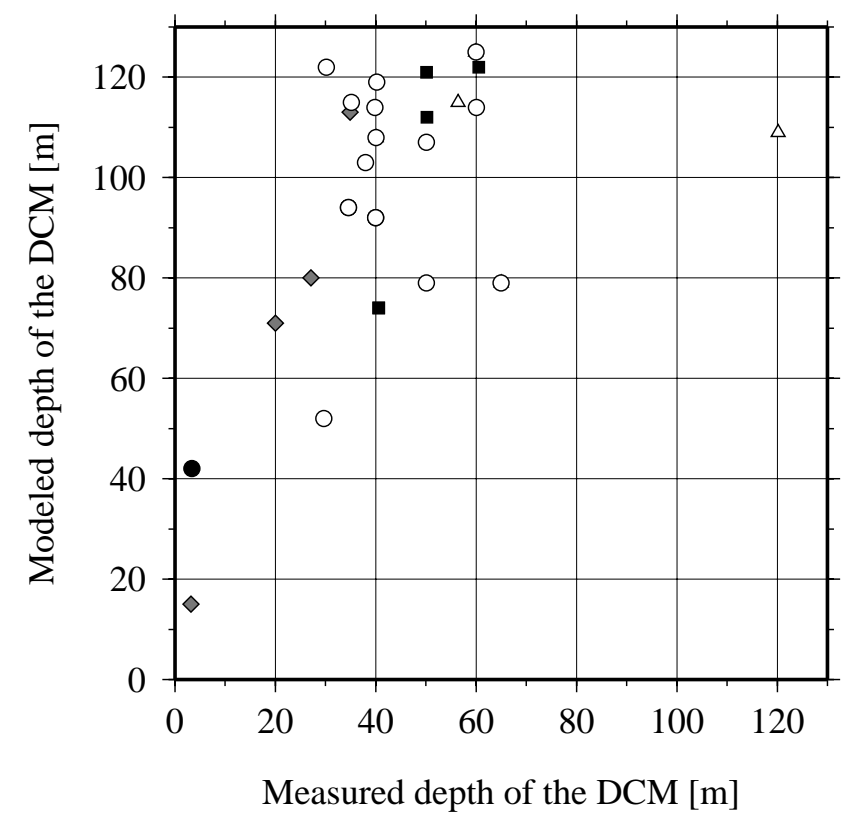

Fig. 11. Predicted versus measured depth of the deep chlorophyll maximum (DCM). Stations from the two river transects are excluded from this comparison because they do not exhibit a DCM (stations 395 to 398 , and 691 to 695 ).

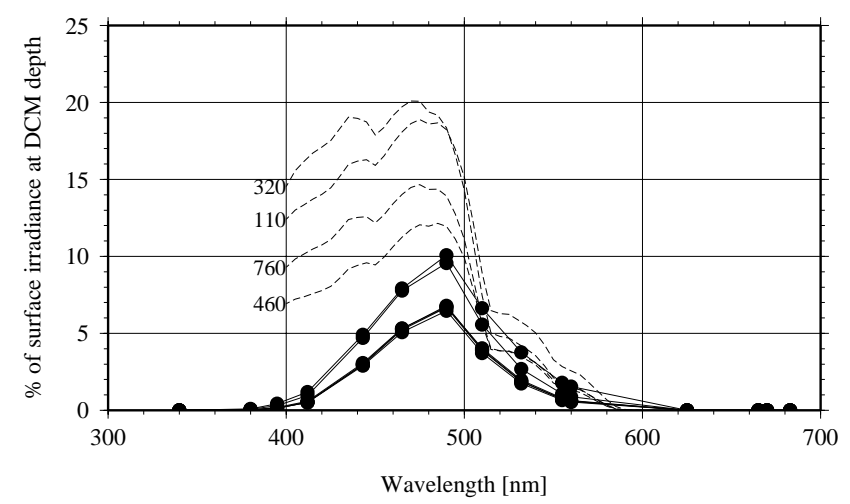

Fig. 12. Percentage of surface irradiance that reaches the depth of the deep chlorophyll maximum (DCM). The percentage is determined either from the radiometry profiles (black dots) or from MM01 (dashed curves) fed with the measured vertical Chl $a$ profile.

(2) estimating the depth profile of Chl $a$ from its surface value (e.g., Morel and Berthon, 1989; Uitz et al., 2006), and (3) propagating incoming spectral irradiance using this Chl $a$ vertical profile and a bio-optical model (MM01 for instance). Subsequent steps that are not considered here are the estimation of absorption of the available light at any depth by phytoplankton, and the transfer of the absorbed energy to photosynthesis (through parameterization of the production versus irradiance curve).

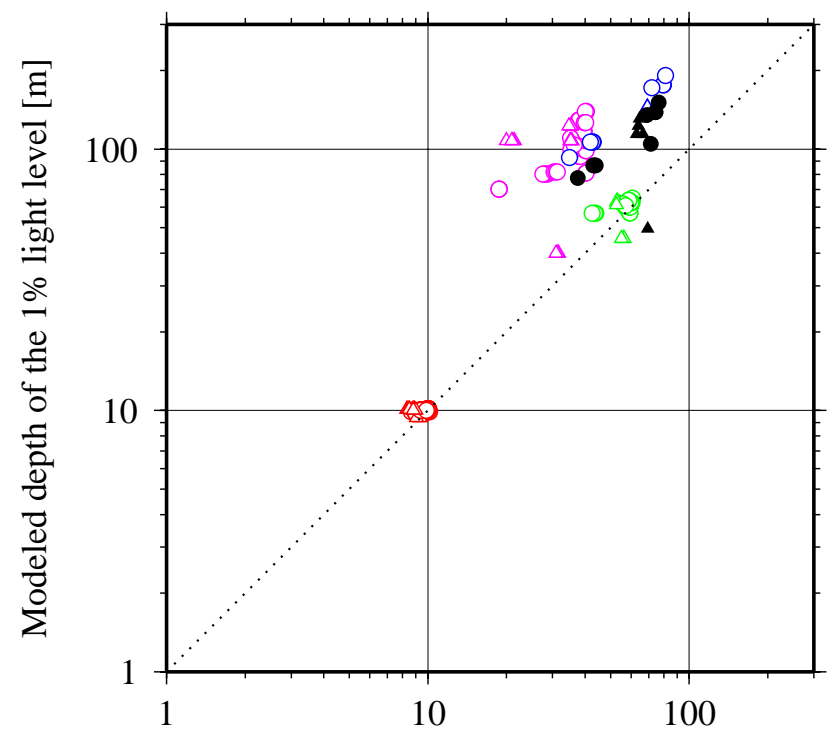

Measured depth of the $1 \%$ light level [m]

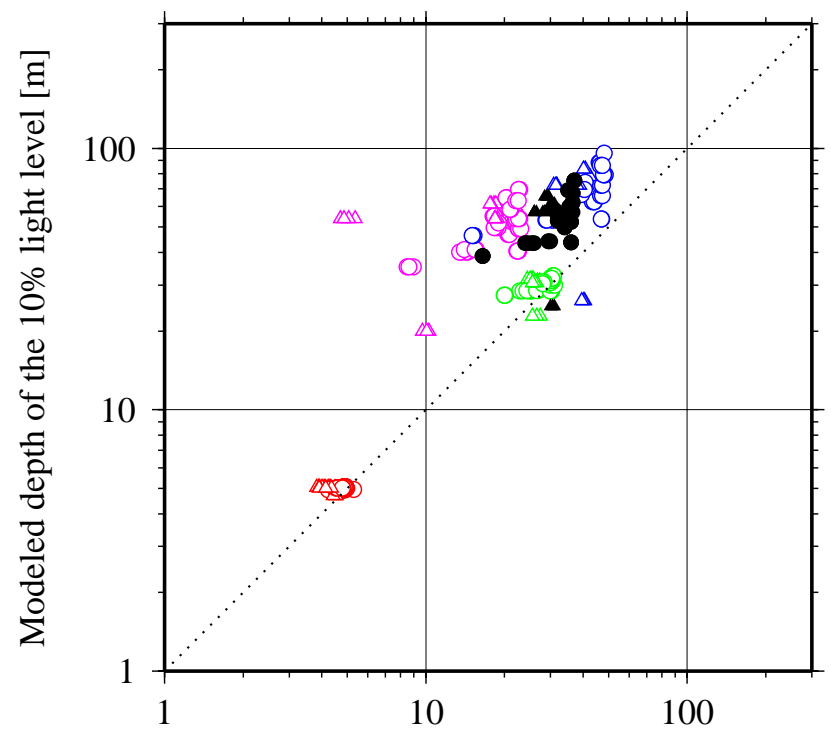

Measured depth of the $10 \%$ light level [m]

Fig. 13. Predicted (MM01) versus measured depth of the $1 \%$ (top) and $10 \%$ (bottom) light levels. Symbols are as for previous figures, i.e., circles for open-ocean stations and triangles for ice-edge stations. Pink, blue, green, red, and black symbols are for $\lambda=380$, 443, 555, $670 \mathrm{~nm}$ and PAR, respectively.

The inappropriateness of current bio-optical algorithms reported here (Fig. 7) shows that step 1 would be wrongly achieved if using them, resulting in a large overestimation of Chl $a$ (Fig. 8). Solving this issue requires using either locally tuned Chl $a$ algorithms or NPP algorithms that are not Chl-based (e.g., Hirawake et al., 2012; Mouw and Yoder, 2005). Combining the retrieval of non-water absorption, $a_{\mathrm{t}}$, from inversion of spectral $R_{\mathrm{rs}}$ with locally tuned models for 
aCDOM (Matsuoka et al., 2013) might help in providing an estimate of particulate absorption $\left(a_{\mathrm{p}}=a_{\mathrm{t}}-a_{\mathrm{CDOM}}\right)$, from which phytoplankton absorption, $a_{\varphi}$, could be derived (e.g., Bricaud and Stramski, 1990) and used as an input to $\mathrm{a}_{\varphi}$-based models.

Step 2 would also be wrongly achieved because the Chl $a$ vertical profile is not correctly reproduced by existing parameterizations, which in particular largely overestimate the depth of the deep chlorophyll maximum (DCM). This is illustrated here using the Morel and Berthon (1989) model, which predicts the shape of the vertical Chl $a$ profile from knowledge of the surface value only. For clear-water stations, the overestimation is generally at least by a factor of two (Fig. 11). Using such a parameterization would largely underestimate the contribution of the DCM to the integrated NPP over the productive column.

Finally, step 3 (irradiance propagation) would also be performed incorrectly (see Fig. 6). This is further illustrated here by comparing the amount and spectral composition of downward irradiance at the measured depth of the DCM. This composition is determined either from the $E_{\mathrm{d}}(\lambda)$ spectra measured at the DCM depth or from spectra modeled from MM01 when fed with the measured Chl $a(z)$ profile (Fig. 12). This comparison clearly shows that there is much less radiation in the near UV and blue part of the spectrum that reaches the DCM in clear waters of the Beaufort Sea than what the model predicts. This further illustrates the strong dimming effect of CDOM absorption in these waters. Another consequence of this effect is that the depth of the productive layer is much reduced as compared to what the model would predict. This is shown in Fig. 13, where the measured and modeled depths of the $1 \%$ and $10 \%$ light levels are compared for different wavelengths and also for PAR. As a consequence, conclusions about the importance of the DCM in the NPP budget of Arctic waters may need to be revised in light of these very peculiar attenuation properties. That aspect was ignored in Arrigo et al. (2011), for instance. Compensating effects may occur among the various parameterizations, however, eventually decreasing errors in NPP predictions as compared to what can be expected from the separate examination of the steps outlined above. NPP cannot be reliably estimated, however, by hoping that such effects indeed occur, which advocates for developing Arctic-specific NPP models.

Another overarching objective of the Malina program is to address interannual to decadal changes of the phytoplankton communities in the Arctic, in particular by assessing Chl $a$ concentrations from ocean color remote sensing observations. The results reported here confirm, however, that remote sensing of Chl $a$ is likely infeasible in the clear waters of the Arctic using conventional techniques based on absorption in the blue part of the spectrum, because of the dominance of absorption by CDOM in this spectral domain. Maximum-band-ratio algorithms such as the OC4-type algorithms (O'Reilly et al., 2000) or simpler relationships such as those shown here (Fig. 9) are more likely to be used for remote sensing of CDOM absorption. The difficulty in getting Chl $a$ from ocean color could be solved by exploiting other parts of the spectrum, e.g., the red (Dall'Olmo et al., 2006; Shen et al., 2010). This could prove useful for moderately to highly turbid waters but not for clear waters, where the marine reflectance in the red is extremely small (Fig. 6a).

Our AOP data set is likely one of the most extensive for the Arctic, and relationships were derivable that can provide regional-scale distribution of CDOM from satellite remote sensing, assuming that the upstream issue of atmospheric corrections has been solved. This data set is, however, still restricted to the Beaufort Sea in August. Additional data are therefore desirable if one aims at a comprehensive view of optical properties in the entire Arctic Ocean, at least during the periods of the year when ocean color remote sensing is possible.

Acknowledgements. We are grateful to the captain and crew of the Canadian Icebreaker CCGS Amundsen. This study was conducted as part of the Malina Scientific Program funded by ANR (Agence nationale de la recherche), INSU-CNRS (Institut national des sciences de l'univers - Centre national de la recherche scientifique), CNES (Centre national d'études spatiales) and ESA (European Space Agency). We thank Joséphine Ras for the HPLC pigment analyses and David Doxaran for providing the SPM data.

Edited by: K. Suzuki

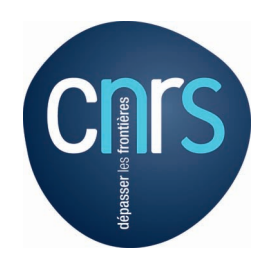

The publication of this article is financed by CNRS-INSU.

\section{References}

Arrigo, K. R., Matrai, P. A., and Van Dijken G. L.: Primary productivity in the Arctic Ocean: impacts of complex optical properties and subsurface chlorophyll maxima on large-scale estimates, J. Geophys. Res., 116, C11022, doi:10.1029/2011JC007273, 2011.

Austin, R. W.: The remote sensing of spectral radiance from below the ocean surface, in: Optical Aspects of Oceanography, edited by: Jerlov, N. G. and Nielsen, E. S., Academic Press, London, 317-344, 1974.

Babin, M., Stramski, D., Ferrari, G. M., Claustre, H., Bricaud, A., Obolensky, G., and Hoepffner, N.: Variations in the light absorption coefficients of phytoplankton, nonalgal particles, and dissolved organic matter in coastal waters around Europe, J. Geophys. Res., 108, 3211, doi:10.1029/2001JC000882, 2003.

Bélanger, S., Ehn, J., and Babin, M.: Impact of Sea Ice on the Retrieval of Water-leaving Reflectance, Chlorophyll a Concentration and Inherent Optical Properties from Satellite Ocean Color Data, Remote Sens. Environ., 111, 51-68, doi:10.1016/j.rse.2007.03.013, 2007. 
Bélanger, S., Babin, M., and Larouche, P.: An empirical ocean color algorithm for estimating the contribution of chromophoric dissolved organic matter to total light absorption in optically complex waters, J. Geophys. Res., 113, C04027, doi:10.1029/2007JC004436, 2008.

Bélanger, S., Cizmeli, S. A., Ehn, J., Matsuoka, A., Doxaran, D., Hooker, S., and Babin, M.: Light absorption and partitioning in Arctic Ocean surface waters: impact of multi year ice melting, Biogeosciences Discuss., 10, 5619-5670, doi:10.5194/bgd-105619-2013, 2013.

Ben Mustapha, S., Bélanger, S., and Larouche, P.: Evaluation of ocean color algorithms in the southeastern Beaufort Sea, Canadian Arctic: New parameterization using SeaWiFS, MODIS and MERIS spectral bands, Can. J. Remote Sens., 54, 535-556, 2012.

Bricaud, A. and Stramski, D.: Spectral absorption coefficients of living phytoplankton and nonalgal biogenous matter: A comparison between the Peru upwelling area and the Sargasso Sea, Limnol. Oceanogr., 35 , 562-582, 1990.

Brown, C. A., Huot, Y., Werdell, P. J., Gentili, B., and Claustre, H.: The origin and global distribution of second order variability in satellite ocean color and its potential applications to algorithm development, Remote Sens. Environ., 112, 4186-4203, doi:10.1016/j.rse.2008.06.008, 2008.

Brunelle, C. B., Larouche, P., and Gosselin, P.: Variability of phytoplankton light absorption in Canadian Arctic seas, J. Geophys. Res., 117, C00G17, doi:10.1029/2011JC007345, 2012.

Carr, M.-E.,Friedrichs, M. A. M., Schmeltz, M., Aité, M. N., Antoine, D., Arrigo, K. R., Asanuma, I., Aumont, O., Barber, R., Behrenfeld, M., Bidigare, R., Buitenhuis, E., Campbell, J., Ciotti, A., Dierssen, H., Dowell, M., Dunne, J., Esaias, W., Gentili, B., Groom, S., Hoepffner, N., Hishisaka, J., Kameda, T., LeQuéré, C., Lohrenz, S., Marra, J., Mélin, F., Moore, K., Morel, A., Reddy, T., Ryan, J., Scardi, M., Smyth, T., Turpie, K., Tilstone, G., Waters, K., Yamanaka, Y.: A comparison of global estimates of marine primary production from ocean color, Deep-Sea Res., Pt. II, 53, 741-770, 2006.

Dall'Olmo, G., Gitelson, A. A., Rundquist, D. C. Leavitt, B. Barrow, T. J., and Holz, C.: Assessing the potential of SeaWiFS and MODIS for estimating chlorophyll concentration in turbid productive waters using red and near-infrared bands, Remote Sens. Environ., 96, 176-187, 2006.

Doxaran, D., Ehn, J., Bélanger, S., Matsuoka, A., Hooker, S., and Babin, M.: Optical characterisation of suspended particles in the Mackenzie River plume (Canadian Arctic Ocean) and implications for ocean colour remote sensing, Biogeosciences, 9, 32133229, doi:10.5194/bg-9-3213-2012, 2012.

Eastman, R. and Warren, S. G.: Interannual variations of Arctic cloud types in relation to sea ice, J. Climate, 23, 4216-4232, doi:10.1175/2010JCLI3492.1, 2010.

Garver, S. A. and Siegel, D. A.: Inherent optical property inversion of ocean color spectra and its biogeochemical interpretation 1 . time series from the Sargasso Sea, J. Geophys. Res., 102, 1860718625, 1997.

Gordon, H. R. and Clark, D. K.: Clear water radiances for atmospheric correction of coastal zone color scanner imagery, Appl. Optics, 20, 4175-4180, 1981.

Hill, V.: The Impacts of Chromophoric Dissolved Organic Material on Surface Ocean Heating in the Chukchi Sea, J. Geophys. Res., 113, doi:10.1029/2007JC004119, 2008.
Hirawake, T., Shinmyo, K., Fujiwara, A., and Saitoh, S.: Satellite remote sensing of primary productivity in the Bering and Chukchi Seas using an absorption-based approach, ICES J. Mar. Sci., 69, 1194-1204, doi:10.1093/icesjms/fss111, 2012.

Hooker, S. B.: The telescoping mount for advanced solar technologies (T-MAST), in: Advances in Measuring the Apparent Optical Properties (AOPs) of Optically Complex Waters, edited by: Morrow, J. H., Hooker, S. B., Booth, C. R., Bernhard, G., Lind, R. N., and Brown, J. W., NASA Tech. Memo. 2010, 215856, NASA Goddard Space Flight Center, Greenbelt, Maryland, 80 pp., 2010.

Hooker, S. B. and Brown, J. W.: Processing of Radiometric Observations of Seawater using Information Technologies (PROSIT): In-Water User Manual, NASA Tech. Memo., NASA Goddard Space Flight Center, Greenbelt, Maryland, in preparation, 2013.

Hooker, S. B., Zibordi, G., Berthon, J.-F., D'Alimonte, D., Maritorena, S., McLean, S., and Sildam, J.: Results of the Second SeaWiFS Data Analysis Round Robin, March 2000 (DARR-30 00), NASA Tech. Memo. 2001-206892, Vol. 15, edited by: Hooker, S. B. and Firestone, E. R., NASA Goddard Space Flight Center, Greenbelt, Maryland, 71 pp., 2001.

Hooker, S. B., Van Heukelem, L., Thomas, C. S., Claustre, H., Ras, J., Barlow, R., Sessions, H., Schluter, L., Perl, J., Trees, C., Stuart, V., et al.: The second SeaWiFS HPLC Analysis RoundRobin Experiment (SeaHARRE-2), in Technical Memorandum NASA/TM-2005-212787, 112 pp., NASA Goddard Space Flight Center, Greenbelt, MD, 2005.

Hooker, S. B., Morrow, J. H., and Matsuoka, A.: Apparent optical properties of the Canadian Beaufort Sea - Part 2: The $1 \%$ and $1 \mathrm{~cm}$ perspective in deriving and validating AOP data products, Biogeosciences, 10, 4511-4527, doi:10.5194/bg-10-4511-2013, 2013.

Joint Global Ocean Flux Stud: JGOFS Core Measurements Protocols, JGOFS Report No. 6, Scientific Committee on Oceanic Research, Bergen, Norway, 40 pp., 1991.

Lee, Z. and $\mathrm{Hu}, \mathrm{C} .:$ Global distribution of Case-1 waters: An analysis from SeaWiFS measurements, Remote Sens. Environ., 101, 270-276, 2006.

Maritorena, S., Siegel, D. A., and Peterson, A.: Optimization of a Semi-Analytical Ocean Colour Model for Global Scale Applications, Appl. Optics, 41, 2705-2714, 2002.

Matsuoka, A., Huot, Y., Shimida, K., Saitoh, S.-I., and Babin, M.: Bio-optical characteristics in the Western Arctic Ocean: Implications for ocean color algorithms, Can. J. Remote Sens., 33, 503-518, 2007.

Matsuoka, A., Larouche, P., Poulin, M., Vincent, W., and Hattori, H.: Phytoplankton community adaptation to changing light levels in the southern Beaufort Sea, Canadian Arctic, Estuar. Coast. Shelf S., 82, 537-546, 2009.

Matsuoka, A., Hill, V., Huot, Y., Babin, M., and Bricaud, A.: Seasonal variability in the light absorption coefficient of phytoplankton, non-algal particles, and colored dissolved organic matter in western Arctic waters: parameterization of the individual components of absorption for ocean color applications, J. Geophys. Res., 116, C02007, doi:10.1029/2009JC005594, 2011.

Matsuoka, A., Bricaud, A., Benner, R., Para, J., Sempéré, R., Prieur, L., Bélanger, S., and Babin, M.: Tracing the transport of colored dissolved organic matter in water masses of the Southern Beaufort Sea: relationship with hydrographic characteristics, Biogeosciences, 9, 925-940, doi:10.5194/bg-9-925-2012, 2012. 
Matsuoka, A., Hooker, S. B., Bricaud, A., Gentili, B., and Babin, M.: Estimating absorption coefficients of colored dissolved organic matter (CDOM) using a semi-analytical algorithm for southern Beaufort Sea waters: application to deriving concentrations of dissolved organic carbon from space, Biogeosciences, 10, 917-927, doi:10.5194/bg-10-917-2013, 2013.

Maykut, G. A. and Grenfell, T. G.: The spectral distribution of light beneath first-year ice in te Arctic ocean, Limnol. Oceanogr., 20, 554-563, 1975.

Mitchell, B. G.: Predictive bio-optical relationships for polar oceans and marginal ice zones, J. Marine Syst., 3, 91-105, 1992.

Mobley, C. D.: Estimation of the remote-sensing reflectance from above-surface measurements, Appl. Optics, 38, 7442-7455, 1999.

Morel, A. and Bélanger, S.: Improved Detection of turbid waters from Ocean Color information, Remote Sens. Environ., 102, 237-249, 2006.

Morel, A. and Berthon, J. F.: Surface pigments, algal biomass profiles, and potential production of the euphotic layer: Relationships reinvestigated in view of remote-sensing applications, Limnol. Oceanogr., 34, 1545-1562, 1989.

Morel, A. and Gentili, B.: Diffuse reflectance of oceanic waters. 2. Bidirectional aspects, Appl. Optics, 32, 6864-6872, 1993.

Morel, A. and Gentili, B.: Diffuse reflectance of oceanic waters. 3. Implication of bidirectionality for the remote-sensing problem, Appl. Optics, 35, 4850-4862, 1996.

Morel, A. and Gentili, B.: A simple band ratio technique to quantify the colored dissolved and detrital organic material from ocean color remotely sensed data, Remote Sens. Environ., 113, 9981011, doi:10.1016/j.rse.2009.01.008, 2009.

Morel, A. and Maritorena, S.: Bio-optical properties of oceanic waters: A reappraisal, J. Geophys. Res., 106, 7763-7780, 2001.

Morel, A. and Prieur, L.: Analysis of variations in ocean color, Limnol. Oceanogr., 22, 709-722, 1977.

Morel, A., Claustre, H., Antoine, D., and Gentili, B.: Natural variability of bio-optical properties in Case 1 waters: attenuation and reflectance within the visible and near-UV spectral domains, as observed in South Pacific and Mediterranean waters, Biogeosciences, 4, 913-925, doi:10.5194/bg-4-913-2007, 2007a.

Morel, A., Huot, Y., Gentili, B., Werdell, P. J., Hooker, S. B., and Franz B. A.: Examining the consistency of products derived from various ocean color sensors in open ocean (Case 1) waters in the perspective of a multi-sensor approach, Remote Sens. Environ., 111, 69-88, 2007b.

Mouw, C. and Yoder, J. A.: Primary production calculations in the Mid-Atlantic Bight, including effects of phytoplankton community size structure, Limnol. Oceanogr., 50, 1232-1243, 2005.

Mueller, J. L.: Overview of measurement and data analysis protocol, in: Ocean Optics Protocols for Satellite Ocean Color Sensor Validation, Revision 2, NASA Tech. Memo. 2000-209966, edited by: Fargion, G. S. and Mueller, J. L., NASA Goddard Space Flight Center, Greenbelt, Maryland, 87-97, 2000.

Mueller, J. L.: Overview of measurement and data analysis protocols, in: Ocean Optics Protocols for Satellite Ocean Color Sensor Validation, Revision 3, Volume 1, NASA Tech. Memo. 2002210004/Rev3-Vol1, edited by: Mueller, J. L. and Fargion, G. S., NASA Goddard Space Flight Center, Greenbelt, Maryland, 123137, 2002.
Mueller, J. L.: Overview of measurement and data analysis methods, in: Ocean Optics Protocols for Satellite Ocean Color Sensor Validation, Revision 4, Volume III: Radiometric Measurements and Data Analysis Protocols, NASA Tech. Memo. 2003211621/Rev4 Vol.III, edited by: Mueller, J. L., Fargoin, G. S., and McClain, C. R., NASA Goddard Space Flight Center, Greenbelt, Maryland, 1-20, 2003.

Mueller, J. L. and Austin, R. W.: Ocean optics protocols for SeaWiFS validation, NASA Tech. Memo. 104566, Vol. 5, edited by: Hooker, S. B. and Firestone, E. R., NASA Goddard Space 30 Flight Center, Greenbelt, Maryland, 43 pp., 1992.

Mueller, J. L. and Austin, R. W.: Ocean optics protocols for SeaWiFS validation, Revision 1, NASA Tech. Memo. 104566, Vol. 25, edited by: Hooker, S. B., Firestone, E. R., and Acker, J. G., NASA Goddard Space Flight Center, Greenbelt, Maryland, 66 pp., 1995.

Mueller, J. L. and Morel, A.: Fundamental definitions, relationships and conventions, in: Ocean Optics Protocols for Satellite Ocean Color Sensor Validation, Revision 4, Volume I: Radiometric Measurements and Data Analysis Protocols, NASA Tech. Memo. 2003-211621/Rev4-Vol.I, edited by: Mueller, J. L., Austin, R. W., Morel, A., Fargion, G. S., and McClain, C. R., 5 NASA Goddard Space Flight Center, Greenbelt, Maryland, 11-30, 2003.

O’Reilly, J. E., Maritorena, S., Mitchell, B. G., Siegel, D. A., Carder, K. L., Garver, S. A., Kahru, M., and McClain, C.: Ocean color chlorophyll algorithms for SeaWiFS, J. Geophys. Res., 103, 24937-24953, 1998.

O'Reilly, J. E., Maritorena, S., O’Brien, M. C., Siegel, D. A., Toole, D., Menzies, D., Smith, R. C., Mueller, J. L., Mitchell, B. G., Kahru, M., Chavez, F. P., Strutton, P., Cota, G. F., Hooker, S. B., McClain, C. R., Carder, K. L., Muller-Karger, F., Harding, L., Magnuson, A., Phinney, D., Moore, G. F., Aiken, J., Arrigo, K. R., Letelier, R., and Culver, M.: SeaWiFS Postlaunch Calibration and Validation Analyses, Part 3. NASA Tech. Memo. 2000206892, Vol. 11, edited by: Hooker, S. B. and Firestone, E. R., NASA Goddard Space Flight Center, 49 pp., 2000.

Pegau, W. S.: Inherent optical properties of the central Arctic surface waters, J. Geophys. Res., 107, 8035, doi:10.1029/2000JC000382, 2002.

Pegau, W. S., Gray, D., and Zaneveld, J. R. V.: Absorption and attenuation of visible and near infrared light in water: dependence on temperature and salinity, Appl. Optics, 36, 6035-6046, 1997.

Preisendorfer, R. W.: Application of radiative transfer theory to light measurements in the sea, Monogr. Int. Union Geod. Geophys. Paris, 10, 11-30, 1961.

Schuur, E. A. G., Bockheim, J., Canadell, J. G., Euskirchen, E., Christopher, B., Goryachkin, S.V., Hagemann, S., Kuhry, P., Lafleur, P. M., Lee, H., Mazhitova, G., Nelson, F. E., Rinke, A., Romanovsky, V. E., Shiklomanov, N., Tarnocai, C., Venevsky, S., Vogel, J. G., and Zimov, S. A.: Vulnerability of Permafrost Carbon to Climate Change: Implications for the Global Carbon Cycle, BioSci., 58, 701-714, doi:10.1641/B580807, 2008.

Shen, F., Zhou, Y., Li, D., Zhu, W., and Salama, Mhd., S.: Medium resolution imaging spectrometer (MERIS) estimation of chlorophyll-a concentration in the turbid sediment-laden waters of the Changjiang (Yangtze) Estuary, Int. J. Remote Sens., 31, 4635-4650, 2010. 
Smith, R. C.: Optical properties of the Arctic upper water, Arctic, 26, 303-313, 1973.

Smith, R. C. and Baker, K. S.: The analysis of ocean optical data, in: Ocean Optics VII, edited by: Blizard, M., Proc. SPIE, 478, 119-126, 1984.

Stroeve, J. C., Serreze, M. C. Fetterer, F., Arbetter, T., Meier, W., Maslanik, J., and Knowles, K.: Tracking the Arctic's shrinking ice cover: Another extreme September minimum in 2004, Geophys. Res. Lett., 32, L04501, 2005.

Thuillier, G., Hersé, M., Simon, P. C., Labs, D., Mandel, H., Gillotay, D., and Foujols, T.: The solar spectral irradiance from 200 to $2400 \mathrm{~nm}$ as measured by the SOLSPEC spectrometer from the Atlas 1-2-3 and EURECA missions, Solar Phys., 214, 1-22, 2003.

Topliss, B. J., Miller, J. R., and Horne, P. W.: Ocean Optical measurements-II. Statistical Analysis of Data from Canadian Eastern Arctic Waters, Cont. Shelf Res., 9, 135-142, 1989.

Uitz, J., Claustre, H., Morel, A., and Hooker, S. B.: Vertical distribution of phytoplankton communities in open ocean: an assessment based on surface chlorophyll, J. Geophys. Res., 111, C08005, doi:10.1029/2005JC003207, 2006.
Van Der Linde, D. W.: Protocol for determination of total suspended matter in oceans and coastal zones, Joint Res. Cent., Brussels, Tech. Note I.98.182, 1998.

Van Heukelem, L. and Thomas, C. S.: Computer-assisted highperformance liquid chromatography method development with applications to the isolation and analysis of phytoplankton pigments, J. Chromatogr. A, 910, 31-49, 2001.

Wang, J. and Cota, G. F.: Remote-sensing reflectance in the Beaufort and Chukchi seas, Appl. Optics, 42, 2754-2765, 2003.

Wang, J., Cota, G., and Ruble, D. A.: Absorption and backscattering in the Beaufort and Chukchi Seas, J. Geophys. Res., 110, C04014, doi:10.1029/2002JC001653, 2005.

Zaneveld, J. R. V., Boss, E., and Barnard, A.: Influence of surface waves on measured and modeled irradiance profiles, Appl. Optics, 40, 1442-1449, 2001.

Zhang, J. L.: Warming of the arctic ice-ocean system is faster than the global average since the 1960s, Geophys. Res. Lett., 32, L19602, 2005. 